\title{
Synthesis and Evaluation of Chalcone-Quinoline Based Molecular Hybrids as Potential Anti-Malarial Agents
}

\author{
Bonani Vinindwa ${ }^{1}$, Godwin Akpeko Dziwornu ${ }^{2}$ and Wayiza Masamba ${ }^{1, *(D)}$ \\ 1 Department of Chemical and Physical Sciences, Faculty of Natural Sciences, Walter Sisulu University, \\ Nelson Mandela Drive, Mthatha 5117, South Africa; athulevinindwa@gmail.com \\ 2 Department of Chemistry, University of Cape Town, Rondebosch 7700, South Africa; \\ godwin.dziwornu@uct.ac.za \\ * Correspondence: wmasamba@wsu.ac.za
}

check for updates

Citation: Vinindwa, B.; Dziwornu, G.A.; Masamba, W. Synthesis and Evaluation of Chalcone-Quinoline Based Molecular Hybrids as Potential Anti-Malarial Agents. Molecules 2021, 26, 4093. https://doi.org/10.3390/ molecules26134093

Academic Editors:

Giuseppe Manfroni,

Tommaso Felicetti and Robert Musioł

Received: 30 May 2021

Accepted: 1 July 2021

Published: 5 July 2021

Publisher's Note: MDPI stays neutral with regard to jurisdictional claims in published maps and institutional affiliations.

Copyright: (c) 2021 by the authors. Licensee MDPI, Basel, Switzerland. This article is an open access article distributed under the terms and conditions of the Creative Commons Attribution (CC BY) license (https:/ / creativecommons.org/licenses/by/ $4.0 /)$.

\begin{abstract}
Molecular hybridization is a drug discovery strategy that involves the rational design of new chemical entities by the fusion (usually via a covalent linker) of two or more drugs, both active compounds and/or pharmacophoric units recognized and derived from known bioactive molecules. The expected outcome of this chemical modification is to produce a new hybrid compound with improved affinity and efficacy compared to the parent drugs. Additionally, this strategy can result in compounds presenting modified selectivity profiles, different and/or dual modes of action, reduced undesired side effects and ultimately lead to new therapies. In this study, molecular hybridization was used to generate new molecular hybrids which were tested against the chloroquine sensitive (NF54) strain of P. falciparum. To prepare the new molecular hybrids, the quinoline nucleus, one of the privileged scaffolds, was coupled with various chalcone derivatives via an appropriate linker to produce a total of twenty-two molecular hybrids in $11 \%-96 \%$ yield. The synthesized compounds displayed good antiplasmodial activity with $\mathrm{IC}_{50}$ values ranging at $0.10-4.45 \mu \mathrm{M}$.
\end{abstract}

Keywords: chalcones; malaria; molecular hybrids; quinoline-sulfonamide; $P$. falciparum

\section{Introduction}

Malaria is a life-threatening disease caused by the Plasmodium parasites that are transmitted to people through the bites of infected female Anopheles mosquitoes [1]. Pregnant women, children under the age of 5 years, and people with weakened immune system are most likely to succumb to the morbidity and transience of the disease [2,3]. In 2019 the estimated malaria cases were 229 million with an approximated death toll of 409,000 [4]. Worldwide, children aged under 5 years, the most vulnerable group, accounted for $67 \%$ of the total malaria deaths in 2019. The World Health Organization (WHO) Africa region accounted for $82 \%$ of all cases and about $10 \%$ in the WHO South-East Asia region. P. falciparum is the most prevalent malaria parasite in the WHO regions of Africa, South-East Asia, the Eastern Mediterranean and the Western Pacific, accounting for $99.7 \%$ of all malaria cases in Africa, 50\% in South-East Asia, 69\% in Eastern Mediterranean, and 65\% in Western Pacific. On the other hand, P. vivax is predominant in the WHO region of the Americas, representing $75 \%$ of malaria cases [5].

For a long time, chloroquine (CQ) remained the antimalarial drug of choice due to its high efficacy, low cost, and tolerable adverse effects. However, large scale use of CQ soon led to the emergence of CQ-resistant parasite strains [2]. Many other alternative drugs followed, including artemisinin combined therapies (ACTs), which for some time became one of the most effective, especially against $P$. falciparum, allowing millions of patients to be cured [1-3,6-8]. However, recent evidence of resistance to artemisinin reported in South Asia and along the Cambodia-Thailand border threatens this strategy [9]. Indeed, as soon as a new drug is introduced, it is just a matter of time before resistance appears. Under these circumstances, there is need to be one step ahead of the malaria parasite by designing 
new strategies in the fight against this pathology. Hence, multi-target hybrid drugs are needed as an alternative or compliment to existing therapies.

Molecular hybridization (MH) is a strategy of rational design of new ligands or prototypes based on the recognition of pharmacophoric subunits in the molecular structure of two or more known bioactive derivatives which through the adequate fusion of these subunits, leads to the formation of new hybrid architectures that maintain pre-selected characteristics of the original templates $[8,10,11]$. Hybrid drugs are designed to counterbalance the known side effects associated with the other hybrid part or to augment its effect through action on another biological target or to interact with multiple targets as one single molecule, lowering the risk of drug-drug interactions and surmount drug resistance [11]. Over the last few years, molecular hybridization has emerged as a novel approach that involves a combination of pharmacophoric elements which are so far known for different enzyme inhibition, leading to active compounds which show a balanced inhibition of enzyme and offers the opportunity to treat different diseases with better tolerated drugs, thus enhancing patient compliance [11]. We therefore sought to apply this concept of molecular hybridization in the design and synthesis of new hybrid compounds based on new hybrid compounds based on the quinoline and chalcone privileged scaffolds connected by an aminoalkylsulphonamide linker.

Privileged structures are core structural units known for binding to proteins, and which can be coupled to other active molecules to generate potential new drugs. 1,3Diarylprop-2-en-1-ones or benzalacetophenones commonly known as chalcones belong to an important class of natural products widely distributed in the plant kingdom. They display an array of biological activities [12] such as antifungal [13], antiparasitic [14], antitumor and antioxidant [15], immunomodulatory [16] antileishmania [17], antimitotic [18], anti-invasive $[19,20]$, anti-inflammatory $[21,22]$ and antimalarial $[23,24]$. Licochalcone (Figure 1I), for example, is a natural compound isolated from Chinese liquorice roots, which has shown potent antiplasmodial activity [25]. Due to this broad range of biological activities, the chalcone molecule is one of the templates extensively used in molecular hybridization. When combined with quinolines, chalcones may be expected to exhibit high antiplasmodial activity.

Of the several antimalarial compounds described in literature, quinoline derivatives are still the dominant class [7]. Furthermore, the diverse pharmacological properties of the quinoline scaffold and derivatives attracted worldwide attention in the last few decades because of their wide occurrence in natural products, and drugs [26]. Synthetic hybrid compounds have been designed to increase the efficacy of quinoline derivatives because the antimalarial hybrid drugs have a lower risk of drug-drug adverse interactions and greater treatment adherence than the combined drugs. Some of the quinoline derivatives shown in Figure 1 have reached the stage of clinical trials. They include chalcone-chloroquinoline (II) [8], AZT-CQ (III) [27], quinine-dihydroartemisinin (IV) [28] and artesunate-mefloquine MEFAS (V) [7].

Quinoline-sulfonamide hybrid compounds such as those in Figure 2, which contain various linker groups connecting arylsulfonamide moieties to the aminoquinoline molecule, have been reported as potential antimalarial drugs [7,29-33]. Though most of them were less active when compared to chloroquine, they showed good antimalarial activity, acting by inhibiting parasite growth without interfering with the integrity of the red blood cell membrane [29]. 
<smiles>C=CC(C)(C)c1cc(/C=C/C(=O)c2ccc(O)cc2)c(OC)cc1O</smiles>

(I)<smiles>CCC(C)n1cc(COc2ccc(/C=C/C(=O)c3ccc(OC)cc3OC)cc2OC)nn1</smiles>

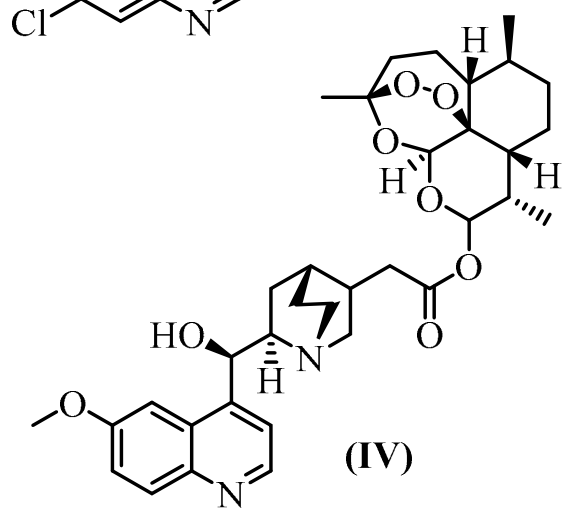<smiles>Cc1cn([C@H]2C[C@H](N)[C@@H](CO)O2)c(=O)n(Cc2cccc(Nc3ccnc4cc(Cl)ccc34)c2)c1=O</smiles>

Figure 1. Structures of licochalcone (I) and molecular hybrids II-V.<smiles>[R]c1ccc(S(=O)(=O)CCNC2CCC2CCCC)cc1</smiles>

(VI)<smiles>[R]NS(=O)(=O)CCNc1ccnc2cc(Cl)ccc12</smiles>

(VII)<smiles>[R]CNc1ccnc2cc(Cl)ccc12</smiles>

(IX)<smiles>[R]S(=O)(=O)Nc1ccnc2cc(Cl)ccc12</smiles>

(X)

Figure 2. Representative quinoline-sulfonamide molecular hybrids VI-X. 
Based on the above properties and literature precedents, we sought in this study to synthesize molecular hybrids comprising of a quinoline-sulfonamide and the relevant chalcones as potential antiplasmodial agents.

\section{Results}

\subsection{Chemistry}

The synthesis of molecular hybrids was carried out in three consecutive steps as outlined in Scheme 1. In a first step, the nucleophilic aromatic substitution reaction $\left(\mathrm{S}_{\mathrm{N}} \mathrm{Ar}\right)$ between 4,7-dichloroquinoline and the relevant diamines ( $\mathrm{n}=2$ and 3 ) afforded the corresponding N-(7-chloroquinol-4-yl) alkyldiamines 2 and 3 in excellent yields (89\% and 95\%, respectively) [7,34], which were condensed with 4-acetylbenzenesulfonyl chloride in the presence of $\mathrm{NaOH}$ to afford 4-acetyl-N-(2-[(7-chloroquinolin-4-yl)amino]alkyl)benzenesulfonamides 4 and 5 in moderate yields ( 29 and $41 \%$, respectively). Finally, a base-catalyzed Claisen-Schmidt coupling of these intermediates with various aryl aldehydes led to the expected molecular hybrids in $11 \%-96 \%$ yield. Table 1 summarizes the overall results in these reactions. Except for compounds 11, 12, 14, 18, 23, and 25, good to excellent yields were obtained in the condensation step. Only trans isomers of the chalcone moiety were obtained as confirmed by the coupling constant between the two olefinin protons $(\sim 15.65 \mathrm{~Hz}$ in all cases).

Table 1. Hybrid compounds with isolated yields.

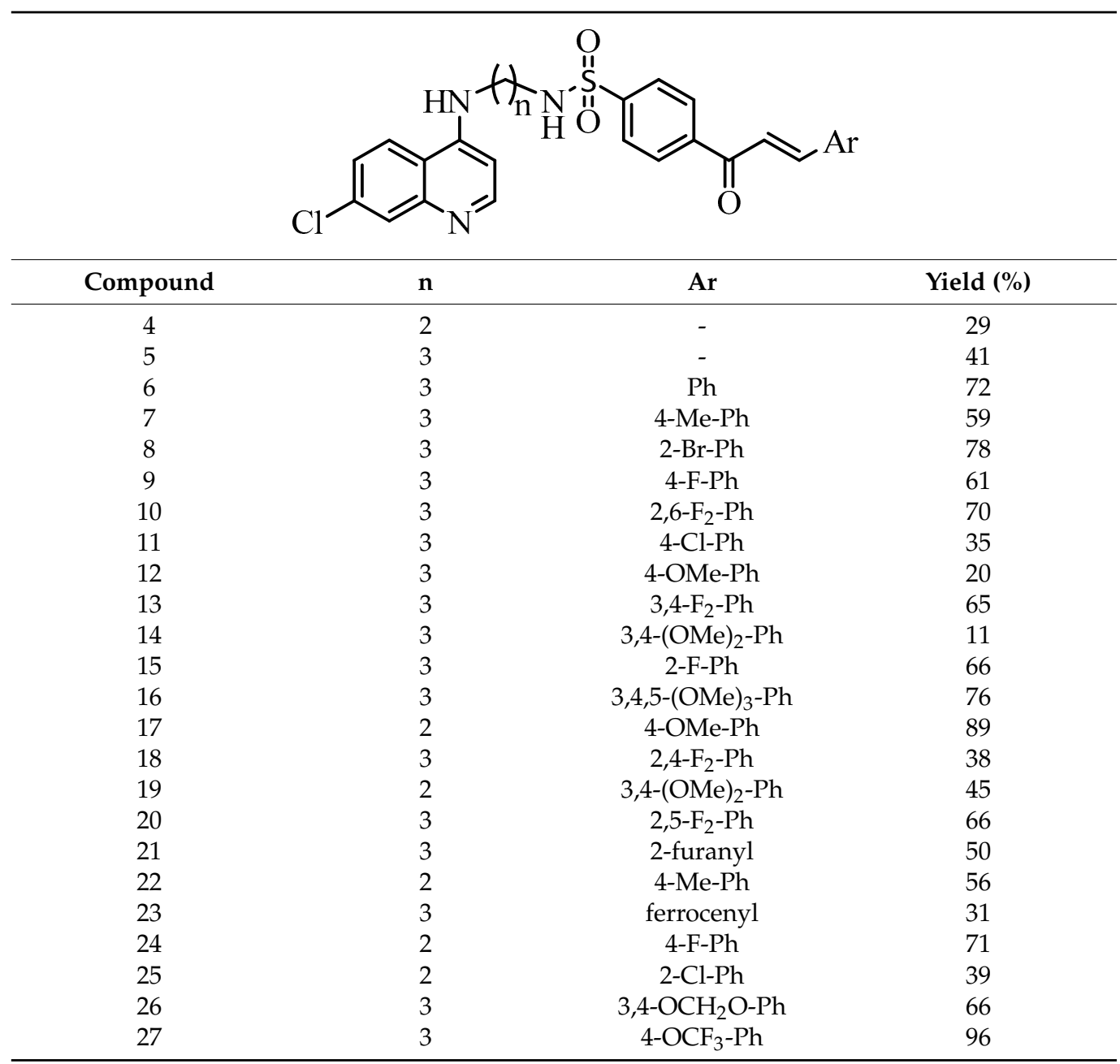




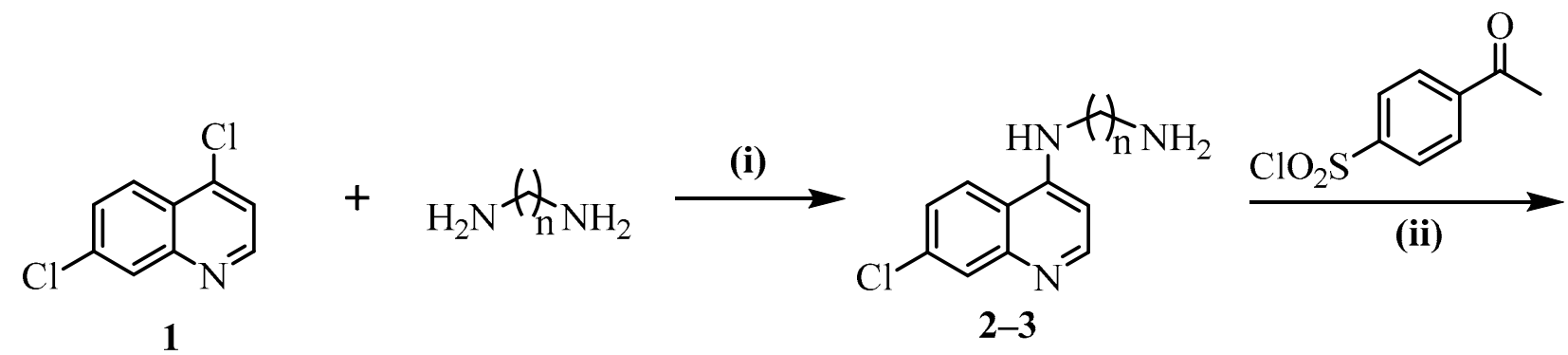<smiles>CC(=O)c1ccc(S(=O)(=O)NC(C)C(C)C)cc1</smiles>

$$
\begin{aligned}
& \mathrm{Ar}=\mathrm{Ph}, 4-\mathrm{CH}_{3}-\mathrm{Ph}, 2-\mathrm{Br}-\mathrm{Ph}, 4-\mathrm{F}-\mathrm{Ph}, 2,6-\mathrm{F}-\mathrm{Ph}, 4-\mathrm{Cl}-\mathrm{Ph}, \\
& \mathrm{n}=2-3 \quad \mathrm{OCH}_{3}-\mathrm{Ph}, 3,4-\mathrm{F}_{2}-\mathrm{Ph}, 3,4-\left(\mathrm{OCH}_{3}\right)_{2}-\mathrm{Ph}, 2-\mathrm{F}-\mathrm{Ph}, 2-\mathrm{Cl}-\mathrm{Ph}, \\
& \\
& 3,4,5-\left(\mathrm{OCH}_{3}\right)_{3}-\mathrm{Ph}, 2,4-\mathrm{F}_{2}-\mathrm{Ph}, 2,5-\mathrm{F}_{2}-\mathrm{Ph}, 3,4-\mathrm{OCH}_{2} \mathrm{O}-\mathrm{Ph}, \\
& 4-\mathrm{OCF}_{3}-\mathrm{Ph}, \text { Ferrocenyl, 2-Furanyl }
\end{aligned}
$$

Scheme 1. Synthesis of molecular hybrids 1-2. Reagents and conditions: (i) appropriate diamine, reflux, 16 h; (ii) 4acetylbenzenesulfonyl chloride, dioxane, $\mathrm{NaOH}$, rt, 24 h; (iii) benzaldehyde derivative, $\mathrm{MeOH}, \mathrm{NaOH}$, reflux overnight.

\subsection{In-Vitro Antiplasmodial Activity Evaluation}

All the synthesized molecular hybrids (6-27) were evaluated for in vitro antiplasmodial activity against the drug-sensitive strain (NF54) of P. falciparum and for cytotoxicity against the Chinese Hamster Ovary $(\mathrm{CHO})$ mammalian cell line using emetine as a reference drug. Aqueous solubility was determined at pH 6.5 (Table 2).

Table 2. In vitro antiplasmodial activity, solubility, and cytotoxicity of the hybrid compounds.

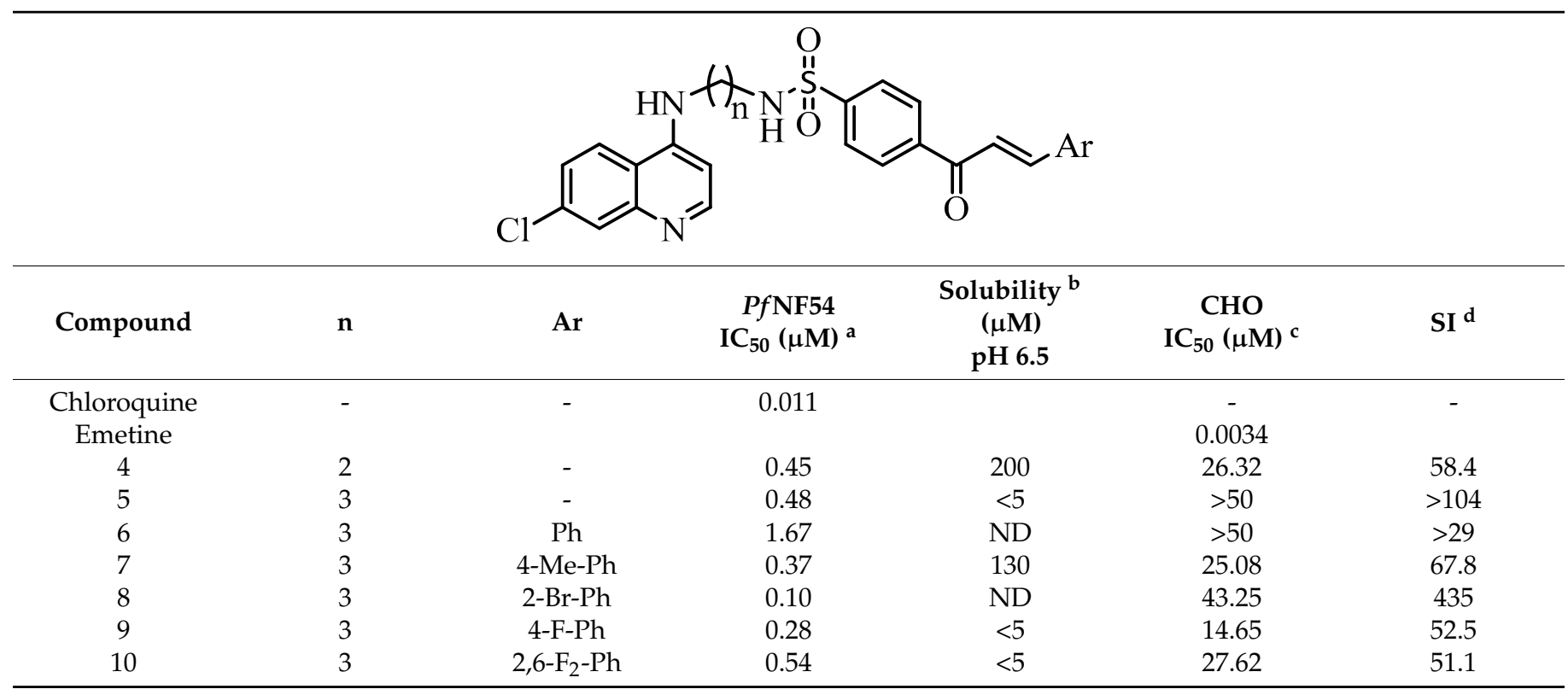


Table 2. Cont.

\begin{tabular}{|c|c|c|c|c|c|c|}
\hline Compound & $\mathbf{n}$ & Ar & $\begin{array}{c}\text { Pf NF54 } \\
\text { IC }_{50}(\mu \mathrm{M})^{a}\end{array}$ & $\begin{array}{c}\text { Solubility } \\
{ }^{b} \\
\text { pH } 6.5\end{array}$ & $\begin{array}{c}\text { CHO } \\
\mathrm{IC}_{50}(\mu \mathrm{M})^{\mathrm{c}}\end{array}$ & $S^{d}$ \\
\hline 11 & 3 & 4-Cl-Ph & 0.10 & ND & 41.2 & 416.2 \\
\hline 12 & 3 & 4-OMe-Ph & 0.11 & ND & 43.3 & 393.6 \\
\hline 13 & 3 & $3,4-\mathrm{F}_{2}-\mathrm{Ph}$ & 2.58 & $<5$ & $>300$ & $>116$ \\
\hline 14 & 3 & $3,4-(\mathrm{OMe})_{2}-\mathrm{Ph}$ & 0.32 & ND & 43.4 & 135.6 \\
\hline 15 & 3 & 2-F-Ph & 0.86 & 5 & 45.53 & 52.9 \\
\hline 16 & 3 & $\begin{array}{c}2,3,4-(\mathrm{OMe})_{3-} \\
\mathrm{Ph}\end{array}$ & 0.58 & 15 & 22.62 & 39.0 \\
\hline 17 & 2 & 4-OMe-Ph & 0.49 & 185 & 17.53 & 35.7 \\
\hline 18 & 3 & $2,4-\mathrm{F}_{2}-\mathrm{Ph}$ & 0.50 & 130 & 22.44 & 45.2 \\
\hline 19 & 2 & $3,4-(\mathrm{OMe})_{2}-\mathrm{Ph}$ & 0.33 & ND & 45.1 & 136.7 \\
\hline 20 & 3 & $2,5-\mathrm{F}_{2}-\mathrm{Ph}$ & 0.79 & & 43.7 & 55.3 \\
\hline 21 & 3 & 2-furanyl & 4.45 & 200 & $>50$ & $>11$ \\
\hline 22 & 2 & 4-Me-Ph & 0.39 & 190 & 24.89 & 63.8 \\
\hline 23 & 3 & ferrocenyl & 1.53 & ND & & ND \\
\hline 24 & 2 & $4-\mathrm{F}-\mathrm{Ph}$ & 0.57 & $<5$ & 14.54 & 25.5 \\
\hline 25 & 2 & 2-Cl-Ph & 0.37 & 19 & 35.41 & 95.7 \\
\hline 26 & 3 & $3,4-\mathrm{OCH}_{2} \mathrm{O}-\mathrm{Ph}$ & 0.69 & 200 & 34.13 & 49.5 \\
\hline 27 & 3 & $4-\mathrm{OCF}_{3}-\mathrm{Ph}$ & 0.51 & ND & 44.04 & 86.3 \\
\hline
\end{tabular}

${ }^{a}$ Mean from $\mathrm{n}$ values of $\geq 2$ independent experiments with sensitive (NF54) strains of $P$. falciparum; ${ }^{\mathrm{b}}$ Aqueous solubility using highperformance liquid chromatography (HPLC)-diode array detector (DAD)-mass spectrometry (MS); ${ }^{\mathrm{c}} \mathrm{CHO}=\mathrm{Chinese}$ hamster ovarian cell line; ${ }^{\mathrm{d}}$ selectivity index $(\mathrm{SI})=(\mathrm{IC} 50(\mathrm{CHO}) / \mathrm{IC} 50($ PfNF54) $)$. ND $=$ not determined.

\section{Discussion}

All synthesized compounds presented good activity with $\mathrm{IC}_{50}$ values ranging from 0.10 to $4.45 \mu \mathrm{M}$ against the NF54 sensitive strain of P. falciparum.

Compared to the unsubstituted molecular hybrid $6\left(\mathrm{IC}_{50}=1.67 \mu \mathrm{M}\right)$, fluoro-substituted derivatives 9, 15, and 24 are all more active (with $\mathrm{IC}_{50}$ (NF54) values of $0.28,0.86$, and $0.57 \mu \mathrm{M}$, respectively), suggesting the importance of electronic effects brought about by the more electronegative fluorine atom. The same trend can be noted with other halogens, such as bromine (compound 8; $\mathrm{IC}_{50}=0.10 \mu \mathrm{M}$ ), chlorine (compound 11, $\mathrm{IC}_{50}=0.10 \mu \mathrm{M}$ ), as well as a methoxy group (compound $12, \mathrm{IC}_{50}=0.11 \mu \mathrm{M}$ ). Compounds $\mathbf{8}, \mathbf{1 1}$, and $\mathbf{1 2}$ were the most active, displaying $\mathrm{IC}_{50}$ values of $0.10,0.10$, and $0.11 \mu \mathrm{M}$, respectively. These compounds were further tested against the multi-drug resistant $\mathrm{K} 1 \mathrm{strain}$ of P. falciparum. Compound 12 showed about two-fold improvement in resistivity index ( $(\mathrm{RI}=5.36), P f \mathrm{~K} 1$ $\mathrm{IC}_{50}=0.59 \mu \mathrm{M}$ ) relative to CQ, making it the frontrunner compound in the present study. Meanwhile, compounds $\mathbf{8}$ and $\mathbf{1 1}$ were less active against the $\mathrm{K} 1$ strain with $\mathrm{IC}_{50}$ values of $2.97 \mu \mathrm{M}$ and $6 \mu \mathrm{M}$, respectively.

In accordance with literature precedents [7], compounds with three methylene groups $(\mathrm{n}=3)$ as linker showed greater activity against $P$. falciparum than those with two methylene groups $(n=2)$. Indeed, the introduction of an additional $\mathrm{CH}_{2}$ group $(\mathrm{n}=3)$ in compound 12 enhances its potency approximately five-fold as compared to compound $\mathbf{1 7}(\mathrm{n}=2)$, while a two-fold increase is noticed going from compound $9(\mathrm{n}=2,0.28 \mu \mathrm{M})$ to compound $24(\mathrm{n}=3,0.57 \mu \mathrm{M})$. In addition, almost all molecular hybridscontaining three methylene groups as linker $(\mathbf{7 - 1 2}, \mathbf{1 4}-\mathbf{2 0})$ were amongst the most active of the series, with $\mathrm{IC}_{50}$ values ranging from $0.10-0.86 \mu \mathrm{M}$.

The less polar methyl group has very little effect on the activity as is observed in compounds 7 and 22 which both have a methyl group in para position and exhibited the same activity $\left(\mathrm{IC}_{50}=0.37 \mu \mathrm{M}\right.$ and $0.39 \mu \mathrm{M}$, respectively).

Compounds $\mathbf{2 1}$ and 23, respectively, containing a 2-furanyl and ferrocenyl as the aromatic rings are among the less active, suggesting the importance of the chalcone unit in the overall activity of the molecule. 
Except for compounds 7, 17, 18, 22, and 26, most compounds were poorly soluble $(<5 \mu \mathrm{M})$. As previously noted, a methyl group has no significant effect on the activity but its presence in compounds 7 and 22 significantly increases the solubility (130 and $190 \mu \mathrm{M}$, respectively) most likely by the disruption of the crystalline packing $[35,36]$. The high solubility of compounds 17 and $26(185$ and $200 \mu \mathrm{M})$ may be attributed to a combination of steric and polar effect of the electronegative oxygen atoms.

\section{Materials and Methods}

\subsection{General}

All commercially available chemicals were purchased from local chemical suppliers. Analytical thin-layer chromatography (TLC) was performed on aluminium-backed silicagel 60 F254 (70-230 mesh) plates. Flash column chromatography was performed with Merck silica-gel 60 (70-230 mesh) on a Biotage Isolera ${ }^{\mathrm{TM}}$ system (Biotage AB, Uppsala, Sweden). Products were characterized by ${ }^{1} \mathrm{H}$ - and ${ }^{13} \mathrm{C}-\mathrm{NMR}$ spectra recorded on a $300 \mathrm{MHz}, 400 \mathrm{MHz}$ or $600 \mathrm{MHz}$ Varian or Bruker NMR spectrometers. Chemical shifts $(\delta)$ are given in ppm downfield from trimethylsilane (TMS) as the internal standard. Coupling constants $(J)$, are recorded in hertz $(\mathrm{Hz})$. Purity was determined by HPLC. The NMR spectra and HPLC-MS spectra of compounds described in this study can be found in Supplementary Materials.

Aqueous solubility. Water solubility was analyzed using a miniaturized shake flask method. Ten millimolar stock solutions of each of the compounds were used to prepare calibration standards $(10-220 \mu \mathrm{M})$ in DMSO. The same $10 \mathrm{mM}$ stock solutions were accurately dispensed in duplicate into 96-well plates, and the DMSO, dried down (MiVac GeneVac, $\left.90 \mathrm{~min}, 37^{\circ} \mathrm{C}\right)$. Thereafter, the samples were reconstituted $(200 \mu \mathrm{M})$ in an aqueous solution and shaken $\left(20 \mathrm{~h}, 25^{\circ} \mathrm{C}\right)$. The solutions were analyzed by means of HPLC-DAD (Agilent1200 Rapid Resolution HPLC with a diode array detector). Best fit calibration curves were constructed using the calibration standards, which were used to determine the aqueous samples' solubility [1,37].

In-vitro anti-plasmodium assay. Compounds were tested using parasite lactate dehydrogenase assay as a marker for parasite survival. The respective stock solutions of CQ diphosphate and test compounds were prepared by dissolving $2 \mathrm{mg} / \mathrm{mL}$ in distilled water (for CQ) and 100\% DMSO for test compounds. The solutions were then stored at $-20{ }^{\circ} \mathrm{C}$, with further dilutions prepared on the day of the experiment. The cultures were synchronized in the ring stage as described previously using $15 \mathrm{~mL}$ of $5 \%(w / v)$ d-sorbitol in water. Synchronous cultures of PfNF54 (CQS) in the late trophozoite stage were prepared to $2 \%$ parasitemia and $2 \%$ hematocrit. Compounds were tested at starting concentrations of $10000 \mathrm{ng} / \mathrm{mL}(1000 \mathrm{ng} / \mathrm{mL}$ for CQ), which were then serially diluted two-fold in complete medium to give 10 concentrations with a final volume of $200 \mu \mathrm{L}$ in each well. Parasites were incubated in the presence of the compounds at $37^{\circ} \mathrm{C}$ in a specialized atmosphere of $4 \% \mathrm{CO}_{2}$ and $3 \% \mathrm{O}_{2}$ in nitrogen for $48 \mathrm{~h}$. Following incubation, $100 \mu \mathrm{L}$ of MalStat reagent and $15 \mu \mathrm{L}$ of resuspended culture were combined, followed by addition of $25 \mu \mathrm{L}$ of nitro blue tetrazolium chloride (NBT). The plates were kept in the dark for about $10 \mathrm{~min}$ to fully develop, and absorbance was measured at $620 \mathrm{~nm}$ on a microplate reader. Raw data were exported to Microsoft Excel for dose-response analysis [1,37].

Cytotoxicity assay. Compounds were screened for in vitro cytotoxicity against Chinese hamster ovarian (CHO) mammalian cell lines, using the 3-(4,5-dimethylthiazol-2yl)-2,5-diphenyltetrazolium bromide (MTT) assay. The reference standard, emetine, was prepared to $2 \mathrm{mg} / \mathrm{mL}$ in distilled water while stock solutions of test compounds were prepared to $20 \mathrm{mg} / \mathrm{mL}$ in $100 \%$ DMSO with the highest concentration of solvent to which the cells were exposed having no measurable effect on the cell viability. The initial concentration of the compounds and control was $100 \mu \mathrm{g} / \mathrm{mL}$, which was serially diluted in complete medium with 10-fold dilutions to give six concentrations, the lowest being $0.001 \mu \mathrm{g} / \mathrm{mL}$. Plates were incubated for $48 \mathrm{~h}$ with $100 \mu \mathrm{L}$ of drug and $100 \mu \mathrm{L}$ of cell suspension in each well and developed afterward by adding $25 \mu \mathrm{L}$ of sterile MTT (Thermo Fisher Scientific) to each well, followed by $4 \mathrm{~h}$ of incubation in the dark. The plates were then centrifuged; the 
medium was aspirated, and $100 \mu \mathrm{L}$ of DMSO was added to dissolve crystals before reading the absorbance at $540 \mathrm{~nm}$. Data were analyzed, and the sigmoidal dose-response was derived using GraphPad Prism v 4.0 software (La Jolla). All experiments were performed for at least three independent biological repeats, each with technical triplicates [1].

\subsection{Experimental Section}

General procedure for preparing 4-acetyl-N-(((7-chloroquinolin-4-yl)amino)alkyl) benzenesulfonamides 4 and 5: 4-acetylbenzenesulfonyl chloride was treated with the respective $\mathrm{N}$-(7-chloroquinolin-4-yl) alkyldiamine (2 or 3) in $7.5 \mathrm{~mL}$ dioxane as solvent and $2.5 \mathrm{~mL}$ $10 \mathrm{M} \mathrm{NaOH}$. The reaction mixture was stirred at room temperature for $24 \mathrm{~h}$ and poured into $50 \mathrm{~mL}$ of ice-cold water. The precipitate was filtered, dried and the crude product purified using Biotage Isolera One ${ }^{\circledR}$ column chromatography in a gradient mixture of $\mathrm{CH}_{2} \mathrm{Cl}_{2} / \mathrm{MeOH}$. Fractions were monitored and collected at 254 and $280 \mathrm{~nm}$. The solvent of the combined fractions was removed under reduced pressure to afford compounds 4 and 5 as white solids in 27 and $41 \%$ yield, respectively.

4-acetyl-N-(2-((7-chloroquinolin-4-yl)amino)ethyl)benzenesulfonamide (4); white solid (0.97 g, $27 \%)$; m.p. $200-204{ }^{\circ} \mathrm{C}$; $\mathrm{Rf}=0.61\left(\mathrm{MeOH}-\mathrm{CH}_{2} \mathrm{Cl}_{2} 1: 9\right) ;{ }^{1} \mathrm{H}$ NMR $\left(600 \mathrm{MHz}, \mathrm{DMSO}-d_{6}\right) \delta$ $8.35(\mathrm{~d}, J=5.4 \mathrm{~Hz}, 1 \mathrm{H}), 8.09(\mathrm{~d}, J=9.1 \mathrm{~Hz}, 1 \mathrm{H}), 8.01(\mathrm{t}, J=5.7 \mathrm{~Hz}, 1 \mathrm{H}), 7.99-7.94(\mathrm{~m}, 2 \mathrm{H})$, 7.90-7.84 (m, 2H), $7.75(\mathrm{~d}, J=2.2 \mathrm{~Hz}, 1 \mathrm{H}), 7.43(\mathrm{dd}, J=9.0,2.3 \mathrm{~Hz}, 1 \mathrm{H}), 7.23(\mathrm{t}, J=5.8 \mathrm{~Hz}$, $1 \mathrm{H}), 6.40(\mathrm{~d}, J=5.5 \mathrm{~Hz}, 1 \mathrm{H}), 3.37(\mathrm{q}, J=6.3 \mathrm{~Hz}, 2 \mathrm{H}), 3.10(\mathrm{t}, J=6.1 \mathrm{~Hz}, 2 \mathrm{H}), 2.56(\mathrm{~s}, 3 \mathrm{H}) .{ }^{13} \mathrm{C}$ NMR $\left(151 \mathrm{MHz}, \mathrm{DMSO}-d_{6}\right) \delta 197.48,152.10,150.20,149.24,144.55,139.67,133.99,129.31$, 127.81, 127.15, 124.63, 124.38, 117.81, 99.02, 42.46, 41.26, 27.34; HPLC-MS (APCI/ESI): Purity $=80 \% . \mathrm{t}_{\mathrm{R}}=0.898 \mathrm{~min}$, calcd. $\mathrm{m} / \mathrm{z}=403.88, \mathrm{~m} / \mathrm{z}[\mathrm{M}]^{+}=404.0$.

4-acetyl-N-(3-((7-chloroquinolin-4-yl)amino)propyl)benzenesulfonamide (5); white solid $(0.144 \mathrm{~g}, 41 \%) ;$ m.p. $181-183{ }^{\circ} \mathrm{C} ; \mathrm{Rf}=0.46\left(\mathrm{MeOH}-\mathrm{CH}_{2} \mathrm{Cl}_{2}, 1: 9\right) ;{ }^{1} \mathrm{H}$ NMR $(600 \mathrm{MHz}, \mathrm{DMSO}-$ $\left.d_{6}\right) \delta 8.36(\mathrm{~d}, J=5.4 \mathrm{~Hz}, 1 \mathrm{H}), 8.19(\mathrm{~d}, J=9.0 \mathrm{~Hz}, 1 \mathrm{H}), 8.08-8.03(\mathrm{~m}, 2 \mathrm{H}), 7.92-7.84(\mathrm{~m}$, $3 \mathrm{H}), 7.77(\mathrm{~d}, J=2.2 \mathrm{~Hz}, 1 \mathrm{H}), 7.43(\mathrm{dd}, J=9.0,2.3 \mathrm{~Hz}, 1 \mathrm{H}), 7.21(\mathrm{t}, J=5.5 \mathrm{~Hz}, 1 \mathrm{H}), 6.38(\mathrm{~d}$, $J=5.5 \mathrm{~Hz}, 1 \mathrm{H}), 3.24(\mathrm{td}, J=6.9,5.3 \mathrm{~Hz}, 2 \mathrm{H}), 2.97-2.90(\mathrm{~m}, 2 \mathrm{H}), 2.59(\mathrm{~s}, 3 \mathrm{H}), 1.77(\mathrm{p}, J=7.0 \mathrm{~Hz}$, 2H). ${ }^{13} \mathrm{C}$ NMR $\left(151 \mathrm{MHz}, \mathrm{DMSO}-d_{6}\right) \delta 197.64,152.17,150.45,149.33,144.60,139.79,133.90$, 129.41, 127.83, 127.24, 124.55, 124.49, 117.85, 99.14, 40.57, 40.31, 28.22, 27.41; HPLC-MS (APCI/ESI): Purity $=100 \% . t_{R}=2.186 \mathrm{~min}$, calcd. $m / z=417.91, m / z[\mathrm{M}]^{+}=418.0$.

General procedure for the synthesis of molecular hybrids 6-27: To a solution of chloroquinolinesulfonamide ( 4 or 5 ) and aryl aldehyde derivatives in methanol ( $2 \mathrm{~mL}), \mathrm{NaOH}$ ( $24 \mathrm{mg}, 6$ mmoles, 2.5 equiv.) was added. The reaction mixture was stirred under reflux overnight. The product was purified using Biotage Isolera One ${ }^{\circledR}$ column chromatography in a gradient mixture of $\mathrm{CH}_{2} \mathrm{Cl}_{2} / \mathrm{MeOH}$. Fractions were monitored and collected at 254 and $280 \mathrm{~nm}$. The solvent of the combined fractions was removed under reduced pressure. In some cases, the products were further purified by recrystallization in $\mathrm{CH}_{2} \mathrm{Cl}_{2}$ and $\mathrm{MeOH}$ to afford crystalline solids with $11-88 \%$ yield.

N-(3-((7-chloroquinolin-4-yl)amino)propyl)-4-cinnamoylbenzenesulfonamide (6); white solid $(0.087 \mathrm{~g}, 72 \%) ;$ m.p. $210-212{ }^{\circ} \mathrm{C}$; $\mathrm{Rf}=0.39\left(\mathrm{MeOH}-\mathrm{CH}_{2} \mathrm{Cl}_{2}, 1: 9\right) ;{ }^{1} \mathrm{H} \mathrm{NMR}(600 \mathrm{MHz}$, DMSO- $\left.d_{6}\right) \delta 8.37(\mathrm{~d}, J=5.4 \mathrm{~Hz}, 1 \mathrm{H}), 8.28-8.23(\mathrm{~m}, 2 \mathrm{H}), 8.21(\mathrm{~d}, J=9.1 \mathrm{~Hz}, 1 \mathrm{H}), 7.97-7.92(\mathrm{~m}$, 2H), 7.92-7.88 (m, 3H), $7.88(\mathrm{~d}, J=13.5 \mathrm{~Hz}, 1 \mathrm{H}), 7.78(\mathrm{~d}, J=15.7 \mathrm{~Hz}, 1 \mathrm{H}), 7.76(\mathrm{~d}, J=2.2 \mathrm{~Hz}$, 1H), 7.64-7.58 (m, 1H), 7.53-7.46 (m, 2H), 7.46-7.36 (m, 1H), $7.30(\mathrm{t}, J=5.4 \mathrm{~Hz}, 1 \mathrm{H}), 6.40$ $(\mathrm{d}, J=5.5 \mathrm{~Hz}, 1 \mathrm{H}), 3.25(\mathrm{q}, J=6.6 \mathrm{~Hz}, 2 \mathrm{H}), 2.96(\mathrm{q}, J=6.7 \mathrm{~Hz}, 2 \mathrm{H}), 1.79(\mathrm{p}, J=7.0 \mathrm{~Hz}$, 2H). ${ }^{13} \mathrm{C}$ NMR $\left(151 \mathrm{MHz}, \mathrm{DMSO}-d_{6}\right) \delta 188.99,167.83,151.87,150.65,145.48,144.52,140.76$, 134.96, 134.06, 133.24, 131.39, 129.77, 129.71, 127.55, 127.31, 124.64, 124.54, 122.35, 117.79, 99.14, 41.01, 40.56, 28.25; HPLC-MS (APCI/ESI): Purity $=100 \%$. tR $=2.470 \mathrm{~min}$, calcd. $m / z=506.0, m / z[\mathrm{M}]^{+}=506.0$.

(E)-N-(3-((7-chloroquinolin-4-yl)amino)propyl)-4-(3-(p-tolyl)acryloyl)benzenesulfonamide (7); white solid (0.0738 g, 59\%); m.p. $209-213{ }^{\circ} \mathrm{C}$; $\mathrm{Rf}=0.48\left(\mathrm{MeOH}-\mathrm{CH}_{2} \mathrm{Cl}_{2}, 1: 9\right) ;{ }^{1} \mathrm{H}$ NMR $\left(600 \mathrm{MHz}, \mathrm{DMSO}-\mathrm{d}_{6}\right) \delta 8.36(\mathrm{~d}, J=5.4 \mathrm{~Hz}, 1 \mathrm{H}), 8.27-8.22(\mathrm{~m}, 2 \mathrm{H}), 8.20(\mathrm{~d}, J=9.0 \mathrm{~Hz}, 1 \mathrm{H})$, 7.96-7.91 (m, 2H), $7.89(\mathrm{t}, J=5.8 \mathrm{~Hz}, 1 \mathrm{H}), 7.83(\mathrm{~d}, J=15.6 \mathrm{~Hz}, 1 \mathrm{H}), 7.81-7.78(\mathrm{~m}, 2 \mathrm{H})$, 7.78-7.73 (m, 2H), $7.42(\mathrm{dd}, J=9.0,2.2 \mathrm{~Hz}, 1 \mathrm{H}), 7.30(\mathrm{~d}, J=7.9 \mathrm{~Hz}, 2 \mathrm{H}), 7.23(\mathrm{t}, J=5.4 \mathrm{~Hz}$, 
$1 \mathrm{H}), 6.39(\mathrm{~d}, J=5.5 \mathrm{~Hz}, 1 \mathrm{H}), 3.24(\mathrm{t}, J=6.5 \mathrm{~Hz}, 2 \mathrm{H}), 2.96(\mathrm{q}, J=6.7 \mathrm{~Hz}, 2 \mathrm{H}), 2.37(\mathrm{~s}, 3 \mathrm{H})$, $1.79(\mathrm{q}, J=7.0 \mathrm{~Hz}, 2 \mathrm{H}) .{ }^{13} \mathrm{C}$ NMR $\left(151 \mathrm{MHz}, \mathrm{DMSO}-d_{6}\right) \delta 188.92,152.13,150.50,149.28$, $145.58,144.43,141.57,140.90,133.92,132.26,130.06,129.71,129.57,127.79,127.29,124.56$, 124.49, 121.28, 117.85, 99.15, 41.03, 40.17, 28.27, 21.60; HPLC-MS (APCI/ESI): Purity = 100\%, $\mathrm{t}_{\mathrm{R}}=2.528 \mathrm{~min}$, calcd. $\mathrm{m} / \mathrm{z}=520.0, \mathrm{~m} / \mathrm{z}[\mathrm{M}]^{+}=520.1$.

(E)-4-(3-(2-bromophenyl)acryloyl)-N-(3-((7-chloroquinolin-4-yl)amino)propyl)benzenesulfon-

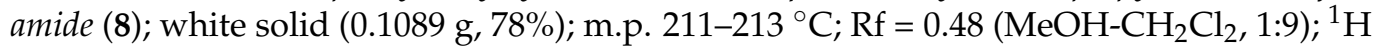
NMR $\left(600 \mathrm{MHz}, \mathrm{DMSO}-d_{6}\right) \delta 8.36(\mathrm{~d}, J=5.4 \mathrm{~Hz}, 1 \mathrm{H}), 8.28-8.24(\mathrm{~m}, 2 \mathrm{H}), 8.23-8.16(\mathrm{~m}, 2 \mathrm{H})$, $8.02(\mathrm{~d}, J=15.5 \mathrm{~Hz}, 1 \mathrm{H}), 7.95(\mathrm{~s}, 1 \mathrm{H}), 7.94(\mathrm{~d}, J=2.0 \mathrm{~Hz}, 1 \mathrm{H}), 7.92-7.85(\mathrm{~m}, 2 \mathrm{H}), 7.80-7.72$ (m, 2H), 7.56-7.49 (m, 1H), 7.49-7.39 (m, 2H), 7.26-7.16 (m, 1H), 6.44-6.36 (m, 1H), $3.24(\mathrm{q}$, mboxemphJ = 6.5 Hz, 2H), $2.96(\mathrm{q}, J=6.6 \mathrm{~Hz}, 2 \mathrm{H}), 1.77(\mathrm{~h}, J=7.1 \mathrm{~Hz}, 2 \mathrm{H}) .{ }^{13} \mathrm{C} \mathrm{NMR}$ $\left(151 \mathrm{MHz}, \mathrm{DMSO}-d_{6}\right) \delta 188.25,151.78,151.75,149.91,148.95,144.22,142.09,139.90,133.74$, $133.33,132.42,129.39,128.82,128.24,127.40,126.82,125.50,124.62,124.05,123.95,117.36$, 98.64, 40.50, 40.46, 27.71; HPLC-MS (APCI/ESI): Purity $=100 \% . \mathrm{t}_{\mathrm{R}}=2.530 \mathrm{~min}, \mathrm{calcd} . \mathrm{m} / \mathrm{z}$ $=584.9, \mathrm{~m} / \mathrm{z}[\mathrm{M}+\mathrm{H}]^{+}=585.9$.

(E)-N-(3-((7-chloroquinolin-4-yl)amino)propyl)-4-(3-(4-fluorophenyl)acryloyl)benzenesulfon-

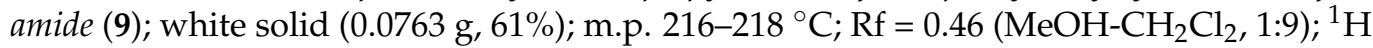
NMR (600 MHz, DMSO- $\left.d_{6}\right) \delta 8.37(\mathrm{~d}, J=5.5 \mathrm{~Hz}, 1 \mathrm{H}), 8.27-8.23(\mathrm{~m}, 2 \mathrm{H}), 8.21(\mathrm{~d}, J=9.0 \mathrm{~Hz}$, $1 \mathrm{H}), 8.02-7.73(\mathrm{~m}, 8 \mathrm{H}), 7.44(\mathrm{dd}, J=8.9,2.2 \mathrm{~Hz}, 1 \mathrm{H}), 7.35-7.28(\mathrm{~m}, 3 \mathrm{H}), 6.41(\mathrm{~d}, J=5.5 \mathrm{~Hz}$, $1 \mathrm{H}), 3.26(\mathrm{q}, J=6.5 \mathrm{~Hz}, 2 \mathrm{H}), 2.96(\mathrm{q}, J=6.6 \mathrm{~Hz}, 2 \mathrm{H}), 1.78(\mathrm{p}, J=7.0 \mathrm{~Hz}, 2 \mathrm{H}) .{ }^{13} \mathrm{C} \mathrm{NMR}$ $\left(151 \mathrm{MHz}, \mathrm{DMSO}-d_{6}\right) \delta 188.86,164.04(\mathrm{~d}, J \mathrm{C}-\mathrm{F}=249.6 \mathrm{~Hz}), 151.65,150.78,144.52,144.23$, $140.73,134.17,131.95,131.93(d, J C-F=8.5 \mathrm{~Hz}), 131.68,129.77,127.34,127.30,124.71,124.57$, 122.23, 117.74, $116.47(\mathrm{~d}, \mathrm{JC}-\mathrm{F}=21.8 \mathrm{~Hz}), 99.14,41.00,40.23,28.24$. HPLC-MS (APCI/ESI); Purity $=100 \%, \mathrm{t}_{\mathrm{R}}=2.476 \mathrm{~min}$, calcd. $\mathrm{m} / \mathrm{z}=524.0, \mathrm{~m} / \mathrm{z}[\mathrm{M}]+=524.0$.

(E)-N-(3-((7-chloroquinolin-4-yl)amino)propyl)-4-(3-(2,6-difluorophenyl)acryloyl)benzenesulfonamide (10); white solid (0.1216 g, 70\%); m.p. 223-225 ${ }^{\circ} \mathrm{C} ; \mathrm{Rf}=0.44\left(\mathrm{MeOH}-\mathrm{CH}_{2} \mathrm{Cl}_{2}, 1: 9\right)$; ${ }^{1} \mathrm{H}$ NMR $\left(600 \mathrm{MHz}, \mathrm{DMSO}-d_{6}\right) \delta 8.34(\mathrm{~d}, J=5.3 \mathrm{~Hz}, 1 \mathrm{H}), 8.17(\mathrm{~d}, J=9.0 \mathrm{~Hz}, 1 \mathrm{H}), 8.15-8.11$ (m, 2H), 7.97-7.92 (m, 2H), $7.90(\mathrm{q}, J=5.5 \mathrm{~Hz}, 1 \mathrm{H}), 7.77(\mathrm{~s}, 1 \mathrm{H}), 7.75-7.68(\mathrm{~m}, 2 \mathrm{H}), 7.59$ (tt, $J=8.2,6.4 \mathrm{~Hz}, 1 \mathrm{H}), 7.40(\mathrm{dd}, J=9.0,2.3 \mathrm{~Hz}, 1 \mathrm{H}), 7.27(\mathrm{t}, J=8.8 \mathrm{~Hz}, 2 \mathrm{H}), 7.16(\mathrm{t}, J=5.5 \mathrm{~Hz}$, $1 \mathrm{H}), 6.37(\mathrm{~d}, J=5.4 \mathrm{~Hz}, 1 \mathrm{H}), 3.23(\mathrm{q}, J=6.5 \mathrm{~Hz}, 2 \mathrm{H}), 2.96(\mathrm{q}, J=6.5 \mathrm{~Hz}, 2 \mathrm{H}), 1.78(\mathrm{p}$, $J=6.9 \mathrm{~Hz}, 2 \mathrm{H}) .{ }^{13} \mathrm{C}$ NMR $\left(151 \mathrm{MHz}, \mathrm{DMSO}-d_{6}\right) \delta 188.48,161.10(\mathrm{~d}, J \mathrm{C}-\mathrm{F}=253.9 \mathrm{~Hz}), 151.81$, 149.92, 148.98, 144.27, 139.69, 133.32, 132.89 (t, JC-F = 11.2 Hz), 130.08, 129.20, 127.42, 127.17, 126.99, 124.02, 123.98, 117.39, 112.49, 112.32 (d, JC-F = 21.7 Hz), 98.63, 40.49, 40.04, 27.78. HPLC-MS (APCI/ESI); Purity $=100 \%, \mathrm{t}_{\mathrm{R}}=2.477 \mathrm{~min}$, calcd. $\mathrm{m} / z=542.0, \mathrm{~m} / z[\mathrm{M}]^{+}=542.0$.

(E)-4-(3-(4-chlorophenyl)acryloyl)-N-(3-((7-chloroquinolin-4-yl)amino)propyl)benzenesulfon-

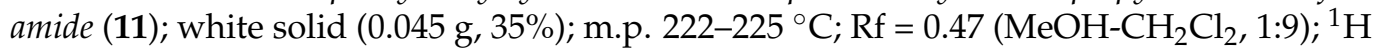
NMR $\left(600 \mathrm{MHz}, \mathrm{DMSO}-\mathrm{d}_{6}\right) \delta 8.35(\mathrm{~d}, J=5.3 \mathrm{~Hz}, 1 \mathrm{H}), 8.27-8.23(\mathrm{~m}, 2 \mathrm{H}), 8.18(\mathrm{~d}, J=9.0 \mathrm{~Hz}$, $1 \mathrm{H}), 7.95(\mathrm{~s}, 1 \mathrm{H}), 7.96-7.88(\mathrm{~m}, 5 \mathrm{H}), 7.77(\mathrm{~d}, J=15.7 \mathrm{~Hz}, 1 \mathrm{H}), 7.74(\mathrm{~d}, J=2.2 \mathrm{~Hz}, 1 \mathrm{H})$, 7.57-7.52 (m, 2H), $7.41(\mathrm{dd}, J=9.0,2.3 \mathrm{~Hz}, 1 \mathrm{H}), 7.18(\mathrm{t}, J=5.4 \mathrm{~Hz}, 1 \mathrm{H}), 6.37(\mathrm{~d}, J=5.4 \mathrm{~Hz}$, $1 \mathrm{H}), 3.23(\mathrm{q}, J=6.5 \mathrm{~Hz}, 2 \mathrm{H}), 2.96(\mathrm{t}, J=6.9 \mathrm{~Hz}, 2 \mathrm{H}), 1.78(\mathrm{p}, J=7.0 \mathrm{~Hz}, 2 \mathrm{H}) .{ }^{13} \mathrm{C} \mathrm{NMR}$ $\left(151 \mathrm{MHz}, \mathrm{DMSO}-d_{6}\right) \delta 188.36,151.80,149.87,148.98,144.08,143.44,140.11,135.37,133.44$, 133.32, 130.69, 129.30, 128.96, 127.45, 126.79, 123.99, 123.93, 122.54, 117.37, 98.63, 48.55, 40.51, 27.73; HPLC-MS (APCI/ESI): Purity $=100 \% . t_{R}=2.527 \mathrm{~min}$, calcd. $m / z=540.4$, $m / z[\mathrm{M}]^{+}=540.0$.

(E)-N-(3-((7-chloroquinolin-4-yl)amino)propyl)-4-(3-(4-methoxyphenyl)acryloyl)benzenesulfonamide (12); white solid (0.0261 g, 20\%); m.p. 221-223 ${ }^{\circ} \mathrm{C}$; $\mathrm{Rf}=0.45\left(\mathrm{MeOH}-\mathrm{CH}_{2} \mathrm{Cl}_{2}, 1: 9\right)$; ${ }^{1} \mathrm{H}$ NMR (600 MHz, DMSO- $\left.d_{6}\right) \delta 8.36(\mathrm{~d}, J=5.4 \mathrm{~Hz}, 1 \mathrm{H}), 8.25-8.21(\mathrm{~m}, 2 \mathrm{H}), 8.19(\mathrm{~d}$, $J=9.0 \mathrm{~Hz}, 1 \mathrm{H}), 7.98-7.91(\mathrm{~m}, 2 \mathrm{H}), 7.91-7.84(\mathrm{~m}, 3 \mathrm{H}), 7.75(\mathrm{~d}, J=3.0 \mathrm{~Hz}, 3 \mathrm{H}), 7.42(\mathrm{dd}$, $J=9.0,2.3 \mathrm{~Hz}, 1 \mathrm{H}), 7.20(\mathrm{t}, J=5.5 \mathrm{~Hz}, 1 \mathrm{H}), 7.06-7.01(\mathrm{~m}, 2 \mathrm{H}), 6.38(\mathrm{~d}, J=5.4 \mathrm{~Hz}, 1 \mathrm{H})$, $3.83(\mathrm{~s}, 3 \mathrm{H}), 3.26-3.21(\mathrm{~m}, 2 \mathrm{H}), 2.96(\mathrm{q}, J=6.6 \mathrm{~Hz}, 2 \mathrm{H}), 1.78(\mathrm{p}, J=7.0 \mathrm{~Hz}, 2 \mathrm{H}) .{ }^{13} \mathrm{C} \mathrm{NMR}$ $\left(151 \mathrm{MHz}, \mathrm{DMSO}-d_{6}\right) \delta 188.29,161.63,151.76,149.93,148.92,145.05,140.62,133.38,131.88$, 131.00, 129.14, 127.40, 127.11, 126.77, 124.04, 123.96, 119.30, 117.37, 114.46, 98.65, 55.40, 54.85, 40.53, 27.76; HPLC-MS (APCI/ESI): Purity $=100 \% . \mathrm{t}_{\mathrm{R}}=2.471 \mathrm{~min}$, calcd. $m / z=536.04$, $m / z[\mathrm{M}]^{+}=536.1$. 
(E)-N-(3-((7-chloroquinolin-4-yl)amino)propyl)-4-(3-(3,4-difluorophenyl)acryloyl)benzenesulfonamide (13); light yellow solid (0.0651 g, 38\%); m.p. $212-214{ }^{\circ} \mathrm{C}$; $\mathrm{Rf}=0.43\left(\mathrm{MeOH}-\mathrm{CH}_{2} \mathrm{Cl}_{2}\right.$, 1:9); ${ }^{1} \mathrm{H}$ NMR (600 MHz, DMSO- $\left.d_{6}\right) \delta 8.35(\mathrm{~d}, J=5.4 \mathrm{~Hz}, 1 \mathrm{H}), 8.28-8.23(\mathrm{~m}, 2 \mathrm{H}), 8.18$ $(\mathrm{d}, J=9.1 \mathrm{~Hz}, 1 \mathrm{H}), 8.13(\mathrm{ddd}, J=12.1,7.9,2.1 \mathrm{~Hz}, 1 \mathrm{H}), 7.96-7.88(\mathrm{~m}, 4 \mathrm{H}), 7.78-7.72(\mathrm{~m}$, $3 \mathrm{H}), 7.54(\mathrm{dt}, J=10.6,8.5 \mathrm{~Hz}, 1 \mathrm{H}), 7.41(\mathrm{dd}, J=9.0,2.3 \mathrm{~Hz}, 1 \mathrm{H}), 7.20(\mathrm{t}, J=5.4 \mathrm{~Hz}$, $1 \mathrm{H}), 6.37(\mathrm{~d}, J=5.4 \mathrm{~Hz}, 1 \mathrm{H}), 3.24(\mathrm{q}, J=6.5 \mathrm{~Hz}, 2 \mathrm{H}), 2.97(\mathrm{q}, J=6.5 \mathrm{~Hz}, 2 \mathrm{H}), 1.78(\mathrm{p}$, $J=7.0 \mathrm{~Hz}, 2 \mathrm{H}) .{ }^{13} \mathrm{C}$ NMR $\left(151 \mathrm{MHz}, \mathrm{DMSO}-d_{6}\right) \delta 188.22,151.71,151.67,149.9$ (d, JC-F $=10.9 \mathrm{~Hz}), 148.92(\mathrm{~d}, J \mathrm{C}-\mathrm{F}=13.3 \mathrm{~Hz}), 142.59,140.01,132.44(\mathrm{~d}, J \mathrm{C}-\mathrm{F}=2.8 \mathrm{~Hz}), 129.51$, 129.34, 127.36, $127.0(\mathrm{~d}, J \mathrm{C}-\mathrm{F}=3.4 \mathrm{~Hz}), 126.98(\mathrm{~d}, \mathrm{JC}-\mathrm{F}=6.9 \mathrm{~Hz}), 123.95,123.01,118.06,118.0$ $(\mathrm{d}, J C-\mathrm{F}=17.4 \mathrm{~Hz}), 117.98,117.35,117.26,117.08,98.63,40.51,40.04,27.73$; HPLC-MS (APCI/ESI): Purity $=100 \% . t_{R}=2.475 \mathrm{~min}$, calcd. $m / z=542.11, m / z[\mathrm{M}]^{+}=542.0$.

(E)-N-(3-((7-chloroquinolin-4-yl)amino)propyl)-4-(3-(3,4-dimethoxyphenyl)acryloyl)benzenesulfonamide (14); white solid (0.0146 g, 11\%); m.p. 222-224 ${ }^{\circ} \mathrm{C} ; \mathrm{Rf}=0.37\left(\mathrm{MeOH}-\mathrm{CH}_{2} \mathrm{Cl}_{2}\right.$, 1:9); ${ }^{1} \mathrm{H}$ NMR (600 MHz, DMSO-d 6 ) $\delta 8.36(\mathrm{~d}, J=5.4 \mathrm{~Hz}, 1 \mathrm{H}), 8.26-8.22(\mathrm{~m}, 2 \mathrm{H}), 8.19$ $(\mathrm{d}, J=9.0 \mathrm{~Hz}, 1 \mathrm{H}), 7.96-7.91(\mathrm{~m}, 2 \mathrm{H}), 7.89(\mathrm{t}, J=5.7 \mathrm{~Hz}, 1 \mathrm{H}), 7.80-7.71(\mathrm{~m}, 3 \mathrm{H}), 7.55(\mathrm{~d}$, $J=2.0 \mathrm{~Hz}, 1 \mathrm{H}), 7.45-7.39(\mathrm{~m}, 2 \mathrm{H}), 7.20(\mathrm{t}, J=5.5 \mathrm{~Hz}, 1 \mathrm{H}), 7.04(\mathrm{~d}, J=8.4 \mathrm{~Hz}, 1 \mathrm{H}), 6.38(\mathrm{~d}, J$ $=5.5 \mathrm{~Hz}, 1 \mathrm{H}), 3.87(\mathrm{~s}, 3 \mathrm{H}), 3.83(\mathrm{~s}, 3 \mathrm{H}), 3.24(\mathrm{q}, J=6.5 \mathrm{~Hz}, 2 \mathrm{H}), 2.96(\mathrm{q}, J=6.6 \mathrm{~Hz}, 2 \mathrm{H}), 1.78$ $(\mathrm{p}, J=7.0 \mathrm{~Hz}, 2 \mathrm{H}) .{ }^{13} \mathrm{C}$ NMR $\left(151 \mathrm{MHz}, \mathrm{DMSO}-d_{6}\right) \delta 188.33,151.76,151.58,149.92,149.03$, 148.92, 145.57, 143.79, 140.67, 133.36, 129.14, 127.39, 127.29, 126.74, 124.25, 124.03, 123.95, 119.38, 117.37, 111.59, 110.96, 98.65, 55.75, 55.62, 40.52, 40.04, 27.76; HPLC-MS (APCI/ESI): Purity $=100 \% . \mathrm{t}_{\mathrm{R}}=2.417 \mathrm{~min}$, calcd. $m / z=566.07, m / z[\mathrm{M}]^{+}=566.1$.

(E)-N-(3-((7-chloroquinolin-4-yl)amino)propyl)-4-(3-(2-fluorophenyl)acryloyl)benzenesulfonamide (15); white solid (0.1093 g, 65\%); m.p. 223-225 ${ }^{\circ} \mathrm{C}$; $\mathrm{Rf}=0.40\left(\mathrm{MeOH}-\mathrm{CH}_{2} \mathrm{Cl}_{2}, 1: 9\right)$; ${ }^{1} \mathrm{H}$ NMR (600 MHz, DMSO-d $\left.)_{6}\right) \delta .35(\mathrm{~d}, J=5.5 \mathrm{~Hz}, 1 \mathrm{H}), 8.25-8.22(\mathrm{~m}, 2 \mathrm{H}), 8.22-8.16$ $(\mathrm{m}, 1 \mathrm{H}), 8.14-8.06(\mathrm{~m}, 1 \mathrm{H}), 7.94(\mathrm{dd}, J=7.6,5.9 \mathrm{~Hz}, 2 \mathrm{H}), 7.92-7.81(\mathrm{~m}, 3 \mathrm{H}), 7.78-7.70$ $(\mathrm{m}, 1 \mathrm{H}), 7.58-7.49(\mathrm{~m}, 1 \mathrm{H}), 7.41(\mathrm{dd}, J=9.0,2.3 \mathrm{~Hz}, 1 \mathrm{H}), 7.37-7.31(\mathrm{~m}, 2 \mathrm{H}), 7.24-7.16(\mathrm{~m}$, $1 \mathrm{H}), 6.37(\mathrm{~d}, J=5.4 \mathrm{~Hz}, 1 \mathrm{H}), 3.24(\mathrm{p}, J=6.5,6.1 \mathrm{~Hz}, 2 \mathrm{H}), 2.96(\mathrm{q}, J=6.5 \mathrm{~Hz}, 2 \mathrm{H}), 1.78$ (p, $J=7.1 \mathrm{~Hz}, 2 \mathrm{H}) .{ }^{13} \mathrm{C}$ NMR $\left(151 \mathrm{MHz}, \mathrm{DMSO}-d_{6}\right) \delta 188.31,160.98(\mathrm{~d}, J \mathrm{C}-\mathrm{F}=252.0 \mathrm{~Hz}), 151.81$, 149.93, 148.98, 144.20, 139.95, 136.08, 133.36, 132.99,132.96 (d, JC-F = 8.8 Hz), 129.29 (d, $J C-F=3.0 \mathrm{~Hz}), 127.42,127.38(\mathrm{~d}, \mathrm{JC}-\mathrm{F}=9.4 \mathrm{~Hz}), 127.01,126.75,124.98(\mathrm{~d}, J \mathrm{C}-\mathrm{F}=3.3 \mathrm{~Hz})$, 124.03, 122.07, 117.40, $116.11(\mathrm{~d}, \mathrm{JC}-\mathrm{F}=21.5 \mathrm{~Hz}), 98.67,40.51,40.04,27.72$. HPLC-MS $(\mathrm{APCI} / \mathrm{ESI}) ;$ Purity $=100 \%, \mathrm{t}_{\mathrm{R}}=2.444 \mathrm{~min}$, calcd. $\mathrm{m} / \mathrm{z}=524.0, \mathrm{~m} / z[\mathrm{M}]^{+}=524.1$.

(E)-N-(3-((7-chloroquinolin-4-yl)amino)propyl)-4-(3-(3,4,5-trimethoxyphenyl)acryloyl)benzenesulfonamide (16); white solid (0.1088 g, 76\%); m.p. $197-200{ }^{\circ} \mathrm{C} ; \mathrm{Rf}=0.48\left(\mathrm{MeOH}-\mathrm{CH}_{2} \mathrm{Cl}_{2}\right.$, 1:9); ${ }^{1} \mathrm{H}$ NMR $\left(600 \mathrm{MHz}, \mathrm{DMSO}-d_{6}\right) \delta 8.37(\mathrm{~d}, J=5.5 \mathrm{~Hz}, 1 \mathrm{H}), 8.24-8.18(\mathrm{~m}, 3 \mathrm{H}), 7.96-7.91$ $(\mathrm{m}, 3 \mathrm{H}), 7.89(\mathrm{t}, J=5.8 \mathrm{~Hz}, 1 \mathrm{H}), 7.82-7.73(\mathrm{~m}, 3 \mathrm{H}), 7.43(\mathrm{dd}, J=9.0,2.2 \mathrm{~Hz}, 1 \mathrm{H}), 7.30(\mathrm{t}$, $J=5.5 \mathrm{~Hz}, 1 \mathrm{H}), 6.95(\mathrm{~d}, J=8.9 \mathrm{~Hz}, 1 \mathrm{H}), 6.40(\mathrm{~d}, J=5.5 \mathrm{~Hz}, 1 \mathrm{H}), 3.89(\mathrm{~s}, 3 \mathrm{H}), 3.88(\mathrm{~s}, 3 \mathrm{H})$, $3.78(\mathrm{~s}, 3 \mathrm{H}), 3.25(\mathrm{t}, J=6.5 \mathrm{~Hz}, 2 \mathrm{H}), 2.96(\mathrm{q}, J=6.6 \mathrm{~Hz}, 2 \mathrm{H}), 1.78(\mathrm{p}, J=7.0 \mathrm{~Hz}, 2 \mathrm{H}) .{ }^{13} \mathrm{C}$ NMR $(151 \mathrm{MHz}$, DMSO-d 6 ) $\delta 188.88,156.58,153.74,151.86,150.66,148.96,144.32,142.24$, $141.13,139.99,134.06,129.60,127.54,127.29,124.65,124.53,124.19,121.27,120.66,117.79$, 109.00, 99.14, 62.03, 60.96, 56.62, 41.02, 40.57, 28.26; HPLC-MS (APCI/ESI): Purity = 100\%, $\mathrm{t}_{\mathrm{R}}=2.459 \mathrm{~min}$, calcd $\mathrm{m} / \mathrm{z}=596.1, \mathrm{~m} / \mathrm{z}[\mathrm{M}]^{+}=596.0$.

(E)-N-(2-((7-chloroquinolin-4-yl)amino)ethyl)-4-(3-(4-methoxyphenyl)acryloyl)benzenesulfonamide (17); yellow solid (0.1144 g, 89\%); m.p. $222-225{ }^{\circ} \mathrm{C}$; $\mathrm{Rf}=0.38\left(\mathrm{MeOH}-\mathrm{CH}_{2} \mathrm{Cl}_{2}, 1: 9\right)$; ${ }^{1} \mathrm{H}$ NMR (600 MHz, DMSO- $\left.d_{6}\right) \delta 8.36(\mathrm{~d}, J=5.3 \mathrm{~Hz}, 1 \mathrm{H}), 8.19-8.14(\mathrm{~m}, 2 \mathrm{H}), 8.10(\mathrm{~d}$, $J=9.0 \mathrm{~Hz}, 1 \mathrm{H}), 8.04(\mathrm{t}, J=5.9 \mathrm{~Hz}, 1 \mathrm{H}), 7.94-7.89(\mathrm{~m}, 2 \mathrm{H}), 7.89-7.83(\mathrm{~m}, 2 \mathrm{H}), 7.78-7.72(\mathrm{~m}$, $2 \mathrm{H}), 7.70(\mathrm{~d}, J=15.6 \mathrm{~Hz}, 1 \mathrm{H}), 7.43(\mathrm{dd}, J=9.0,2.2 \mathrm{~Hz}, 1 \mathrm{H}), 7.23(\mathrm{t}, J=5.7 \mathrm{~Hz}, 1 \mathrm{H}), 7.06-7.01$ $(\mathrm{m}, 2 \mathrm{H}), 6.41(\mathrm{~d}, J=5.5 \mathrm{~Hz}, 1 \mathrm{H}), 3.83(\mathrm{~s}, 3 \mathrm{H}), 3.38(\mathrm{q}, J=6.3 \mathrm{~Hz}, 2 \mathrm{H}), 3.11(\mathrm{q}, J=6.3 \mathrm{~Hz}$, 2H). ${ }^{13} \mathrm{C}$ NMR $\left(151 \mathrm{MHz}, \mathrm{DMSO}-d_{6}\right) \delta 188.64,162.11,152.19,150.19,149.36,145.45,144.25$, 141.05, 133.96, 131.48, 129.56, 127.90, 127.63, 127.20, 124.62, 124.35, 119.78, 117.84, 114.95, 99.02, 55.91, 42.55, 41.29; HPLC-MS (APCI/ESI): Purity $=100 \%, \mathrm{t}_{\mathrm{R}}=2.440 \mathrm{~min}$, calcd. $\mathrm{m} / \mathrm{z}$ $=522.12, \mathrm{~m} / \mathrm{z}[\mathrm{M}]^{+}=522.0$.

(E)-N-(3-((7-chloroquinolin-4-yl)amino)propyl)-4-(3-(2,4-difluorophenyl)acryloyl)benzenesulfonamide (18); light yellow solid (0.01118 g, 65\%); m.p. 216-218 ${ }^{\circ} \mathrm{C}$; $\mathrm{Rf}=0.39 \mathrm{MeOH}-\mathrm{CH}_{2} \mathrm{Cl}_{2}$, 
1:9); ${ }^{1} \mathrm{H}$ NMR (600 MHz, DMSO- $\left.d_{6}\right) \delta 8.35(\mathrm{dd}, J=5.4,1.9 \mathrm{~Hz}, 1 \mathrm{H}), 8.25-8.16(\mathrm{~m}, 3 \mathrm{H}), 8.07-$ $8.03(\mathrm{~m}, 1 \mathrm{H}), 7.94(\mathrm{~d}, J=8.3 \mathrm{~Hz}, 1 \mathrm{H}), 7.94-7.86(\mathrm{~m}, 2 \mathrm{H}), 7.82-7.72(\mathrm{~m}, 2 \mathrm{H}), 7.46-7.37(\mathrm{~m}$, $2 \mathrm{H}), 7.29-7.19(\mathrm{~m}, 2 \mathrm{H}), 6.38(\mathrm{dd}, J=5.5,2.2 \mathrm{~Hz}, 1 \mathrm{H}), 3.24(\mathrm{t}, J=6.4 \mathrm{~Hz}, 2 \mathrm{H}), 2.98-2.90$ $(\mathrm{m}, 2 \mathrm{H}), 1.77(\mathrm{~h}, J=6.8 \mathrm{~Hz}, 2 \mathrm{H}) .{ }^{13} \mathrm{C}$ NMR $\left(151 \mathrm{MHz}, \mathrm{DMSO}-d_{6}\right) \delta 188.19,162.54(\mathrm{~d}$, $J C-F=100.6 \mathrm{~Hz}), 161.32(\mathrm{~d}, J \mathrm{C}-\mathrm{F}=242.3 \mathrm{~Hz}), 151.64,151.62,149.97,148.80,144.18,143.95$, $133.42,130.31,129.10(\mathrm{~d}, J \mathrm{C}-\mathrm{F}=58.9 \mathrm{~Hz}), 128.91,126.73,124.06,123.98,123.60,118.97(\mathrm{~d}$, $J C-F=3.7 \mathrm{~Hz}), 117.34,112.65(\mathrm{~d}, J \mathrm{C}-\mathrm{F}=3.4 \mathrm{~Hz}), 112.50(\mathrm{~d}, J \mathrm{C}-\mathrm{F}=3.7 \mathrm{~Hz}), 98.64,40.49$, 39.90, 27.70; HPLC-MS (APCI/ESI): Purity $=96 \%, \mathrm{t}_{\mathrm{R}}=2.464 \mathrm{~min}$, calcd. $m / z=541.99$, $m / z[\mathrm{M}]^{+}=542.0$.

(E)-N-(2-((7-chloroquinolin-4-yl)amino)ethyl)-4-(3-(3,4-dimethoxyphenyl)acryloyl)benzenesulfonamide (19); yellow solid (0.0609 g, 45\%); m.p. 223-225 ${ }^{\circ} \mathrm{C}$; $\mathrm{Rf}=0.44\left(\mathrm{MeOH}-\mathrm{CH}_{2} \mathrm{Cl}_{2}\right.$, 1:9); ${ }^{1} \mathrm{H}$ NMR (600 MHz, DMSO-d $\left.d_{6}\right) \delta 8.36(\mathrm{~d}, J=5.4 \mathrm{~Hz}, 1 \mathrm{H}), 8.18(\mathrm{~d}, J=8.2 \mathrm{~Hz}, 2 \mathrm{H})$, $8.09(\mathrm{~d}, J=9.0 \mathrm{~Hz}, 1 \mathrm{H}), 7.92(\mathrm{~d}, J=8.4 \mathrm{~Hz}, 2 \mathrm{H}), 7.77-7.71(\mathrm{~m}, 3 \mathrm{H}), 7.54(\mathrm{~d}, J=2.0 \mathrm{~Hz}, 1 \mathrm{H})$, $7.42(\mathrm{ddd}, J=7.9,5.9,2.1 \mathrm{~Hz}, 2 \mathrm{H}), 7.22(\mathrm{t}, J=5.8 \mathrm{~Hz}, 1 \mathrm{H}), 7.04(\mathrm{~d}, J=8.4 \mathrm{~Hz}, 1 \mathrm{H}), 6.41(\mathrm{~d}$, $J=5.4 \mathrm{~Hz}, 1 \mathrm{H}), 3.86(\mathrm{~s}, 3 \mathrm{H}), 3.83(\mathrm{~s}, 3 \mathrm{H}), 3.38(\mathrm{q}, J=6.4 \mathrm{~Hz}, 2 \mathrm{H}), 3.17(\mathrm{~d}, J=4.7 \mathrm{~Hz}, 2 \mathrm{H}) .{ }^{13} \mathrm{C}$ NMR $\left(151 \mathrm{MHz}\right.$, DMSO- $\left.d_{6}\right) \delta 188.24,151.83,151.79,151.57,149.65,149.02,145.49,143.73$, $140.64,133.42,129.08,127.47,127.31,126.68,124.33,124.19,123.83,119.40,117.35,111.60$, 110.98, 98.52, 55.75, 48.56, 42.04; HPLC-MS (APCI/ESI): Purity $=100 \% . \mathrm{t}_{\mathrm{R}}=2.387 \mathrm{~min}$, calcd. $m / z=552.04, m / z[\mathrm{M}]^{+}=552.1$.

(E)-N-(3-((7-chloroquinolin-4-yl)amino)propyl)-4-(3-(2,5-difluorophenyl)acryloyl)benzenesuIfonamide (20); light yellow solid (0.1134 g, 66\%); m.p. 219-221 ${ }^{\circ} \mathrm{C}$; $\mathrm{Rf}=0.39\left(\mathrm{MeOH}-\mathrm{CH}_{2} \mathrm{Cl}_{2}\right.$, 1:9); ${ }^{1} \mathrm{H}$ NMR $\left(600 \mathrm{MHz}\right.$, DMSO- $\left.d_{6}\right) \delta 8.35(\mathrm{~d}, J=5.5 \mathrm{~Hz}, 1 \mathrm{H}), 8.27-8.23(\mathrm{~m}, 2 \mathrm{H}), 8.19(\mathrm{~d}$, $J=9.0 \mathrm{~Hz}, 1 \mathrm{H}), 8.11-8.02(\mathrm{~m}, 1 \mathrm{H}), 7.99(\mathrm{~d}, J=15.7 \mathrm{~Hz}, 1 \mathrm{H}), 7.95-7.87(\mathrm{~m}, 2 \mathrm{H}), 7.79(\mathrm{dd}$, $J=15.8,1.4 \mathrm{~Hz}, 1 \mathrm{H}), 7.77-7.71(\mathrm{~m}, 1 \mathrm{H}), 7.46-7.37(\mathrm{~m}, 3 \mathrm{H}), 7.24(\mathrm{t}, J=5.5 \mathrm{~Hz}, 1 \mathrm{H}), 6.38(\mathrm{~d}$, $J=5.5 \mathrm{~Hz}, 1 \mathrm{H}), 3.24(\mathrm{q}, J=6.6 \mathrm{~Hz}, 2 \mathrm{H}), 2.97(\mathrm{q}, J=6.6 \mathrm{~Hz}, 2 \mathrm{H}), 1.78(\mathrm{p}, J=7.0 \mathrm{~Hz}, 2 \mathrm{H}) .{ }^{13} \mathrm{C}$ NMR (151 MHz, DMSO-d $\left.d_{6}\right) \delta 188.07,158.59(\mathrm{~d}, J \mathrm{C}-\mathrm{F}=180.3 \mathrm{~Hz}), 156.97(\mathrm{~d}, J \mathrm{C}-\mathrm{F}=188.9 \mathrm{~Hz})$, 155.42, 151.50, 150.04, 148.63, 144.30, 139.72, 134.64, 133.47, 129.39, 127.22, 126.84, 125.00, $124.99(\mathrm{~d}, J \mathrm{C}-\mathrm{F}=3.5 \mathrm{~Hz}), 123.99,119.44(\mathrm{~d}, J \mathrm{C}-\mathrm{F}=9.0 \mathrm{~Hz}), 117.30,117.07(\mathrm{~d}, J \mathrm{C}-\mathrm{F}=8.9 \mathrm{~Hz})$, $114.87(\mathrm{~d}, \mathrm{JC}-\mathrm{F}=2.6 \mathrm{~Hz}), 98.63,40.46,40.04,27.73$; HPLC-MS (APCI/ESI): Purity $=100 \%$. $t_{\mathrm{R}}=2.490 \mathrm{~min}$, calcd. $m / z=542.11, \mathrm{~m} / z[\mathrm{M}]^{+}=542.0$.

(E)-N-(3-((7-chloroquinolin-4-yl)amino)propyl)-4-(3-(furan-2-yl)acryloyl)benzenesulfonamide (21); light yellow solid (0.0798 g, 50\%); m.p. 222-224 ${ }^{\circ} \mathrm{C}$; $\mathrm{Rf}=0.41\left(\mathrm{MeOH}-\mathrm{CH}_{2} \mathrm{Cl}_{2}, 1: 9\right) ;{ }^{1} \mathrm{H}$ NMR $\left(600 \mathrm{MHz}\right.$, DMSO- $\left.d_{6}\right) \delta 8.36(\mathrm{~d}, J=5.5 \mathrm{~Hz}, 1 \mathrm{H}), 8.21(\mathrm{~d}, J=9.0 \mathrm{~Hz}, 1 \mathrm{H}), 8.18-8.14(\mathrm{~m}$, $2 \mathrm{H}), 7.97-7.91(\mathrm{~m}, 2 \mathrm{H}), 7.93-7.85(\mathrm{~m}, 2 \mathrm{H}), 7.76(\mathrm{~d}, J=2.2 \mathrm{~Hz}, 1 \mathrm{H}), 7.60(\mathrm{~d}, J=15.4 \mathrm{~Hz}, 1 \mathrm{H})$, $7.44(\mathrm{dd}, J=9.4,7.1 \mathrm{~Hz}, 1 \mathrm{H}), 7.15(\mathrm{~d}, J=3.4 \mathrm{~Hz}, 1 \mathrm{H}), 6.72(\mathrm{dd}, J=3.5,1.8 \mathrm{~Hz}, 1 \mathrm{H}), 6.40(\mathrm{~d}, J$ $=5.6 \mathrm{~Hz}, 1 \mathrm{H}), 3.27-3.21(\mathrm{~m}, 2 \mathrm{H}), 2.95(\mathrm{q}, J=6.6 \mathrm{~Hz}, 2 \mathrm{H}), 1.78(\mathrm{p}, J=6.9 \mathrm{~Hz}, 2 \mathrm{H}) .{ }^{13} \mathrm{C}$ NMR $\left(151 \mathrm{MHz}\right.$, DMSO- $\left.d_{6}\right) \delta 187.89,151.21,150.98,150.24,148.29,146.57,143.89,140.21,133.63$, $131.27,129.05,126.91,126.88,124.19,124.05,118.39,117.83,117.25,113.27,98.63,48.56$, 40.48, 27.72. HPLC-MS (APCI/ESI); Purity $=100 \%, \mathrm{t}_{\mathrm{R}}=2.368 \mathrm{~min}$, calcd. $\mathrm{m} / z=495.97$, $m / z[\mathrm{M}]^{+}=496.0$.

(E)-N-(2-((7-chloroquinolin-4-yl)amino)ethyl)-4-(3-(p-tolyl)acryloyl)benzenesulfonamide (22); yellow solid $\left(0.0704\right.$ g, 56\%); m.p. $184-187^{\circ} \mathrm{C}$; $\mathrm{Rf}=0.39\left(\mathrm{MeOH}-\mathrm{CH}_{2} \mathrm{Cl}_{2}, 1: 9\right) ;{ }^{1} \mathrm{H}$ NMR $\left(600 \mathrm{MHz}, \mathrm{DMSO}-d_{6}\right) \delta 8.36(\mathrm{~d}, J=5.4 \mathrm{~Hz}, 1 \mathrm{H}), 8.20-8.14(\mathrm{~m}, 2 \mathrm{H}), 8.10(\mathrm{~d}, J=9.1 \mathrm{~Hz}, 1 \mathrm{H})$, $8.05(\mathrm{t}, J=5.9 \mathrm{~Hz}, 1 \mathrm{H}), 7.94-7.89(\mathrm{~m}, 2 \mathrm{H}), 7.82-7.71(\mathrm{~m}, 5 \mathrm{H}), 7.43(\mathrm{dd}, J=9.0,2.2 \mathrm{~Hz}, 1 \mathrm{H})$, $7.33-7.23(\mathrm{~m}, 3 \mathrm{H}), 6.41(\mathrm{~d}, J=5.5 \mathrm{~Hz}, 1 \mathrm{H}), 3.38(\mathrm{q}, J=6.3 \mathrm{~Hz}, 2 \mathrm{H}), 3.11(\mathrm{q}, J=6.3 \mathrm{~Hz}, 2 \mathrm{H})$, $2.36(\mathrm{~s}, 3 \mathrm{H}) .{ }^{13} \mathrm{C}$ NMR $\left(151 \mathrm{MHz}\right.$, DMSO- $\left.d_{6}\right) \delta 188.77,152.10,150.25,149.25,145.49,144.38$, $141.55,140.81,134.01,132.27,130.06,129.63,129.55,127.81,127.21,124.64,124.37,121.24$, 117.82, 99.02, 42.54, 41.29, 21.60; HPLC-MS (APCI/ESI): Purity $=100 \%, \mathrm{t}_{\mathrm{R}}=2.481 \mathrm{~min}$, calcd. $m / z=506.02, m / z[\mathrm{M}]^{+}=506.0$.

(E)-N-(2-((7-chloroquinolin-4-yl)amino)ethyl)-4-(3-ferrocenyl)acryloyl)benzenesulfonamide 23;

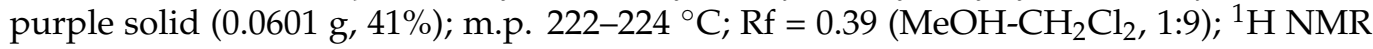
$\left(600 \mathrm{MHz}\right.$, DMSO- $\left.d_{6}\right) \delta 8.41(\mathrm{~d}, J=7.5 \mathrm{~Hz}, 1 \mathrm{H}), 8.17-7.19(\mathrm{~m}, 14 \mathrm{H}), 6.56-6.47(\mathrm{~m}, 6 \mathrm{H}), 3.15$ $(\mathrm{q}, J=6.6 \mathrm{~Hz}, 2 \mathrm{H}), 2.95(\mathrm{q}, J=6.6 \mathrm{~Hz}, 2 \mathrm{H}), 1.76(\mathrm{p}, J=7.1 \mathrm{~Hz}, 2 \mathrm{H}) .{ }^{13} \mathrm{C}$ NMR $(151 \mathrm{MHz}$, DMSO-d $\left.d_{6}\right) \delta 187.29,151.60,149.75,147.70,143.47,140.72,133.16,132.01,128.84,127.47$, 
126.63, 123.90, 118.48, 78.66, 71.51, 69.54, 69.35, 54.73, 48.44, 27.65; HPLC-MS (APCI/ESI): Purity $=100 \%, \mathrm{t}_{\mathrm{R}}=2.498 \mathrm{~min}$, calcd. $\mathrm{m} / \mathrm{z}=613.9, \mathrm{~m} / \mathrm{z}[\mathrm{M}]^{+}=614.0$.

(E)-N-(2-((7-chloroquinolin-4-yl)amino)ethyl)-4-(3-(4-fluorophenyl)acryloyl)benzenesulfonamide (24); light yellow solid (0.0893 g, 71\%); m.p. $222-224{ }^{\circ} \mathrm{C} \mathrm{Rf}=0.45\left(\mathrm{MeOH}-\mathrm{CH}_{2} \mathrm{Cl}_{2}, 1: 9\right)$; ${ }^{1} \mathrm{H}$ NMR (600 MHz, DMSO-d 6 ) $\delta 8.37(\mathrm{~d}, J=5.5 \mathrm{~Hz}, 1 \mathrm{H}), 8.20-8.14(\mathrm{~m}, 2 \mathrm{H}), 8.10(\mathrm{~d}$, $J=9.1 \mathrm{~Hz}, 1 \mathrm{H}), 8.05(\mathrm{t}, J=5.9 \mathrm{~Hz}, 1 \mathrm{H}), 8.03-7.95(\mathrm{~m}, 2 \mathrm{H}), 7.94-7.89(\mathrm{~m}, 2 \mathrm{H}), 7.84-7.71$ $(\mathrm{m}, 3 \mathrm{H}), 7.43(\mathrm{dd}, J=9.0,2.3 \mathrm{~Hz}, 1 \mathrm{H}), 7.36-7.28(\mathrm{~m}, 3 \mathrm{H}), 6.42(\mathrm{~d}, J=5.5 \mathrm{~Hz}, 1 \mathrm{H}), 3.39(\mathrm{q}$, $J=6.3 \mathrm{~Hz}, 2 \mathrm{H}), 3.12(\mathrm{q}, J=6.3 \mathrm{~Hz}, 2 \mathrm{H}) .{ }^{13} \mathrm{C} \mathrm{NMR}\left(151 \mathrm{MHz}, \mathrm{DMSO}-d_{6}\right) \delta 188.71,163.22$ $(d, J C-F=249.6$ Hz), 151.83, 150.41, 148.92, 144.48, 144.14, 134.14, 131.93 (d, JC-F = 8.5 Hz), $131.88,131.68,129.68,127.21,124.72,124.42,122.17,117.75,116.54$ (d, JC-F = 21.8 Hz), 116.40, 99.02, 42.55, 41.30; HPLC-MS (APCI/ESI): Purity $=100 \%, \mathrm{t}_{\mathrm{R}}=2.427 \mathrm{~min}$, calcd. $m / z=509.98, m / z[\mathrm{M}]^{+}=510.0$.

(E)-4-(3-(2-chlorophenyl)acryloyl)-N-(2-((7-chloroquinolin-4-yl)amino)ethyl)benzenesulfonamide (25); light yellow solid (0.0508 g, 39\%); m.p. 209-211 ${ }^{\circ} \mathrm{C} \mathrm{Rf}=0.42\left(\mathrm{MeOH}-\mathrm{CH}_{2} \mathrm{Cl}_{2}, 1: 9\right)$; ${ }^{1} \mathrm{H}$ NMR $\left(600 \mathrm{MHz}, \mathrm{DMSO}-d_{6}\right) \delta 8.43(\mathrm{td}, J=8.7,5.9 \mathrm{~Hz}, 1 \mathrm{H}), 8.30-8.25(\mathrm{~m}, 2 \mathrm{H}), 8.25-6.90$ $(\mathrm{m}, 12 \mathrm{H}), 6.75(\mathrm{~d}, J=9.7 \mathrm{~Hz}, 1 \mathrm{H}), 6.55(\mathrm{~d}, J=9.1 \mathrm{~Hz}, 1 \mathrm{H}), 3.45(\mathrm{dd}, J=12.1,5.8 \mathrm{~Hz}, 2 \mathrm{H}), 3.07$ $(\mathrm{q}, J=6.3 \mathrm{~Hz}, 2 \mathrm{H}) .{ }^{13} \mathrm{C}$ NMR $\left(151 \mathrm{MHz}, \mathrm{DMSO}-d_{6}\right) \delta 192.18,144.60,139.91,138.38,134.46$, $132.86,132.51,131.08,130.64,130.00,129.74,129.60,128.22,127.39,127.19,126.90,125.90$, 125.55, 124.93, 124.13, 121.62, 99.04, 42.75, 41.23; HPLC-MS (APCI/ESI): Purity = 82\%, $\mathrm{t}_{\mathrm{R}}=2.451 \mathrm{~min}$, calcd. $\mathrm{m} / \mathrm{z}=526.4, \mathrm{~m} / z[\mathrm{M}]^{+}=526.0$.

(E)-4-(3-(benzo[d][1,3]dioxol-5-yl)acryloyl)-N-(3-((7-chloroquinolin-4-yl)amino)propyl)benzenesulfonamide (26); yellow solid (0.058 g, 66\%); m.p. 222-224 ${ }^{\circ} \mathrm{C}$; $\mathrm{Rf}=0.46\left(\mathrm{MeOH}-\mathrm{CH}_{2} \mathrm{Cl}_{2}\right.$, 1:9); ${ }^{1} \mathrm{H}$ NMR (600 MHz, DMSO- $\left.d_{6}\right) \delta 8.35(\mathrm{~d}, J=5.4 \mathrm{~Hz}, 1 \mathrm{H}), 8.25(\mathrm{~d}, J=8.2 \mathrm{~Hz}, 2 \mathrm{H}), 8.19$ $(\mathrm{d}, J=9.0 \mathrm{~Hz}, 1 \mathrm{H}), 7.94-7.64(\mathrm{~m}, 7 \mathrm{H}), 7.42(\mathrm{dd}, J=9.0,2.3 \mathrm{~Hz}, 1 \mathrm{H}), 7.36(\mathrm{dd}, J=8.1,1.7 \mathrm{~Hz}$, $1 \mathrm{H}), 7.19(\mathrm{t}, J=5.6 \mathrm{~Hz}, 1 \mathrm{H}), 7.01(\mathrm{~d}, J=8.0 \mathrm{~Hz}, 1 \mathrm{H}), 6.38(\mathrm{~d}, J=5.5 \mathrm{~Hz}, 1 \mathrm{H}), 6.12(\mathrm{~s}, 2 \mathrm{H})$, $3.24(\mathrm{q}, J=6.5 \mathrm{~Hz}, 2 \mathrm{H}), 2.96(\mathrm{q}, J=6.6 \mathrm{~Hz}, 2 \mathrm{H}), 1.78(\mathrm{p}, J=7.1 \mathrm{~Hz}, 2 \mathrm{H}) .{ }^{13} \mathrm{C}$ NMR $(151 \mathrm{MHz}$, DMSO-d 6 ) $\delta 188.16,151.79,149.89,149.85,148.97,148.12,145.05,143.86,140.50,133.34$, 129.17, 129.00, 127.43, 126.75, 126.30, 124.01, 123.94, 119.71, 117.38, 108.55, 107.02, 101.72, 98.64, 40.53, 40.48, 27.76. HPLC-MS (APCI/ESI); Purity $=100 \%, \mathrm{t}_{\mathrm{R}}=2.423 \mathrm{~min}$, calcd. $\mathrm{m} / \mathrm{z}$ $=550.0, m / z[\mathrm{M}]^{+}=550.0$.

(E)-N-(3-((7-chloroquinolin-4-yl)amino)propyl)-4-(3-(4-(trifluoromethoxy)phenyl)acryloyl)benzenesulfonamide (27); light yellow solid (0.0901 g, 96\% yield); m.p. 223-225 ${ }^{\circ} \mathrm{C}$; $\mathrm{Rf}=0.43$ $\left(10 \% \mathrm{MeOH}-\mathrm{CH}_{2} \mathrm{Cl}_{2}\right) ;{ }^{1} \mathrm{H}$ NMR $\left(600 \mathrm{MHz}, \mathrm{DMSO}-d_{6}\right) \delta 8.36(\mathrm{~d}, J=5.5 \mathrm{~Hz}, 1 \mathrm{H}), 8.27-8.23$ $(\mathrm{m}, 2 \mathrm{H}), 8.20(\mathrm{~d}, J=8.9 \mathrm{~Hz}, 1 \mathrm{H}), 8.10-8.02(\mathrm{~m}, 2 \mathrm{H}), 7.96-7.86(\mathrm{~m}, 4 \mathrm{H}), 7.79(\mathrm{~d}, J=15.7 \mathrm{~Hz}$, $1 \mathrm{H}), 7.74(\mathrm{~d}, J=2.3 \mathrm{~Hz}, 1 \mathrm{H}), 7.49-7.41(\mathrm{~m}, 2 \mathrm{H}), 7.30(\mathrm{t}, \mathrm{J}=5.3 \mathrm{~Hz}, 1 \mathrm{H}), 6.40(\mathrm{~d}, J=5.5 \mathrm{~Hz}, 1 \mathrm{H})$, $3.25(\mathrm{q}, \mathrm{J}=6.6 \mathrm{~Hz}, 2 \mathrm{H}), 2.96(\mathrm{q}, J=6.5 \mathrm{~Hz}, 2 \mathrm{H}), 1.78(\mathrm{p}, J=7.1 \mathrm{~Hz}, 2 \mathrm{H}) .{ }^{13} \mathrm{C}$ NMR $(151 \mathrm{MHz}$, DMSO-d $\left.d_{6}\right) \delta 188.41,151.30,150.20,149.74,148.38,144.12,143.13,140.08,134.20,133.61$, $130.99,129.33(d, J C-F=25.3 \mathrm{~Hz}), 126.97,126.74,124.17,124.04,123.00,121.26,117.42,117.27$, 98.64, 40.49, 40.04, 27.72; HPLC-MS (APCI/ESI): Purity = 100\%. $\mathrm{t}_{\mathrm{R}}=2.559 \mathrm{~min}, \mathrm{MW}=590.1$, $m / z[\mathrm{M}]^{+}=590.0$.

\section{Conclusions}

In conclusion, 22 molecular hybrids were successfully synthesized in good to excellent yields. They were all fully characterized using spectroscopic techniques such as ${ }^{1} \mathrm{H}$ - and ${ }^{13} \mathrm{C}-\mathrm{NMR}$ spectroscopy and HPLC-MS. These compounds were evaluated for in vitro antiplasmodial activity against the chloroquine sensitive (NF54) strain of $P$. falciparum and displayed promising activity with $\mathrm{IC}_{50}$ values ranging at $0.10-4.45 \mu \mathrm{M}$. The frontrunner compound 12 showed improved resistivity index compared to $C Q$, as well as good safety profile $(S I=393.6)$.

Supplementary Materials: The following are available online. The NMR spectra and HPLC-MS spectra of compounds described in this study are available online.

Author Contributions: Conceptualization, W.M.; methodology, W.M.; validation, G.A.D., W.M.; formal analysis, B.V., G.A.D. and W.M.; investigation, B.V., G.A.D. and W.M.; resources, W.M.; data 
curation, B.V., G.A.D. and W.M.; writing—original draft preparation, W.M.; writing-review and editing, G.A.D., W.M.; supervision, G.A.D., W.M.; project administration, W.M.; funding acquisition, W.M. All authors have read and agreed to the published version of the manuscript.

Funding: This research was funded by the South African Medical Research Council and The Directorate of Research and Innovation of Walter Sisulu University.

Institutional Review Board Statement: Not applicable.

Informed Consent Statement: Not applicable.

Data Availability Statement: Not applicable.

Acknowledgments: The logistical support received from the Drug Discovery and Development Centre (H3D) at the University of Cape Town is gratefully acknowledged.

Conflicts of Interest: The authors declare no conflict of interest.

Sample Availability: Samples of the compounds are available from the authors.

\section{References}

1. Mueller, R.; Reddy, V.; Nchinda, A.T.; Mebrahtu, F.; Taylor, D.; Lawrence, N.; Tanner, L.; Barnabe, M.; Eyermann, C.J.; Zou, B.; et al. Lerisetron Analogues with Antimalarial Properties: Synthesis, Structure-Activity Relationship Studies, and Biological Assessment. ACS Omega 2020, 5, 6967-6982. [CrossRef]

2. Kumar, S.; Singh, R.K.; Sharma, R.; Murthy, R.; Bhardwaj, T. Design, synthesis and evaluation of antimalarial potential of polyphosphazene linked combination therapy of primaquine and dihydroartemisinin. Eur. J. Pharm. Sci. 2015, 66, 123-137. [CrossRef]

3. Rudrapal, M.; Chetia, D. Endoperoxide antimalarials: Development, structural diversity and pharmacodynamic aspects with reference to 1,2,4-trioxane-based structural scaffold. Drug Des. Dev. Ther. 2016, 10, 3575-3590. [CrossRef] [PubMed]

4. WHO. The "World Malaria Report 2020" at a Glance. 2020. Available online: https://www.who.int/teams/global-malariaprogramme/reports/world-malaria-report-2020 (accessed on 25 May 2021).

5. WHO. The "World Malaria Report 2019" at a Glance. 2019. Available online: https://www.who.int/news-room/feature-stories/ detail/world-malaria-report-2019 (accessed on 25 May 2021).

6. Sherman, I.W. Malaria: Parasite Biology, Pathogenesis and Protection, in Malaria: Parasite Biology, Pathogenesis and Protection; ASM Press: Washington, DC, USA, 1998.

7. Pinheiro, L.C.D.S.; Boechat, N.; Ferreira, M.D.L.G.; Júnior, C.C.; Jesus, A.M.; Leite, M.M.; Souza, N.B.; Krettli, A.U. AntiPlasmodium falciparum activity of quinoline-sulfonamide hybrids. Bioorgan. Med. Chem. 2015, 23, 5979-5984. [CrossRef] [PubMed]

8. Guantai, E.M.; Ncokazi, K.; Egan, T.J.; Gut, J.; Rosenthal, P.J.; Smith, P.J.; Chibale, K. Design, synthesis and in vitro antimalarial evaluation of triazole-linked chalcone and dienone hybrid compounds. Bioorgan. Med. Chem. 2010, 18, 8243-8256. [CrossRef] [PubMed]

9. Smit, F.J.; Van Biljon, R.; Birkholtz, L.-M.; N'Da, D.D. Synthesis and in vitro biological evaluation of dihydroartemisinyl-chalcone esters. Eur. J. Med. Chem. 2015, 90, 33-44. [CrossRef] [PubMed]

10. Muregi, F.W.; Ishih, A. Next-generation antimalarial drugs: Hybrid molecules as a new strategy in drug design. Drug Dev. Res. 2009, 71, 20-32. [CrossRef] [PubMed]

11. Viegas-Junior, C.; Danuello, A.; da Silva Bolzani, V.; Barreiro, E.J.; Fraga, C.A.M. Molecular Hybridization: A Useful Tool in the Design of New Drug Prototypes. Curr. Med. Chem. 2007, 14, 1829-1852. [CrossRef]

12. Vandekerckhove, S.; D’Hooghe, M. Quinoline-based antimalarial hybrid compounds. Bioorgan. Med. Chem. 2015, 23, 5098-5119. [CrossRef]

13. Lopez, S.N.; Castelli, M.V.; Zacchino, S.A.; Domınguez, J.N.; Lobo, G.; Charris-Charris, J.; Cortes, J.G.; Ribas, J.C.; Devia, C.; Rodriguez, A.M.; et al. In vitro antifungal evaluation and structure-activity relationships of a new series of chalcone derivatives and synthetic analogues, with inhibitory properties against polymers of the fungal cell wall. Bioorgan. Med. Chem. 2001, 9, 1999-2013. [CrossRef]

14. Konieczny, M.T.; Horowska, B.; Kunikowski, A.; Konopa, J.; Wierzba, K.; Yamada, Y.; Asao, T. Synthesis of Polyhydroxylated Derivatives of Phenyl Vinyl Sulfone as Structural Analogs of Chalcones. Synthesis 2001, 2001, 1363-1367. [CrossRef]

15. Go, M.L.; Wu, X.; Liu, X.L. Chalcones: An Update on Cytotoxic and Chemoprotective Properties. Curr. Med. Chem. 2005, 12, 483-499. [CrossRef] [PubMed]

16. Barfod, L.; Kemp, K.; Hansen, M.; Kharazmi, A. Chalcones from Chinese liquorice inhibit proliferation of T cells and production of cytokines. Int. Immunopharmacol. 2002, 2, 545-555. [CrossRef]

17. Tomar, V.; Bhattacharjee, G.; Kamaluddin; Rajakumar, S.; Srivastava, K.; Puri, S. Synthesis of new chalcone derivatives containing acridinyl moiety with potential antimalarial activity. Eur. J. Med. Chem. 2010, 45, 745-751. [CrossRef] 
18. Ducki, S.; Forrest, R.; Hadfield, J.A.; Kendall, A.; Lawrence, N.J.; McGown, A.T.; Rennison, D. Potent antimitotic and cell growth inhibitory properties of substituted chalcones. Bioorgan. Med. Chem. Lett. 1998, 8, 1051-1056. [CrossRef]

19. Parmar, V.S.; Sharma, N.K.; Husain, M.; Watterson, A.C.; Kumar, J.; A Samuelson, L.; Cholli, A.L.; Prasad, A.K.; Malhotra, S.; Kumar, N.; et al. Synthesis, characterization and in vitro anti-invasive activity screening of polyphenolic and heterocyclic compounds. Bioorgan. Med. Chem. 2003, 11, 913-929. [CrossRef]

20. Mukherjee, S.; Kumar, V.; Prasad, A.K.; Raj, H.G.; Bracke, M.E.; Olsen, C.E.; Jain, S.C.; Parmar, V.S. Synthetic and biological activity evaluation studies on novel 1,3-diarylpropenones. Bioorgan. Med. Chem. 2001, 9, 337-345. [CrossRef]

21. Hsieh, H.-K.; Tsao, L.-T.; Wang, J.-P.; Lin, C.-N. Synthesis and Anti-inflammatory Effect of Chalcones. J. Pharm. Pharmacol. 2010, 52, 163-171. [CrossRef] [PubMed]

22. Hsieh, H.; Lee, T.; Wang, J.; Wang, J.; Lin, C. Synthesis and Anti-inflammatory Effect of Chalcones and Related Compounds. Pharm. Res. 1998, 15, 39-46. [CrossRef]

23. Liu, M.; Wilairat, P.; Go, M.-L. Antimalarial Alkoxylated and Hydroxylated Chalones: Structure-Activity Relationship Analysis. J. Med. Chem. 2001, 44, 4443-4452. [CrossRef]

24. Gutteridge, C.E.; Nichols, D.A.; Curtis, S.M.; Thota, D.S.; Vo, J.V.; Gerena, L.; Montip, G.; Asher, C.O.; Diaz, D.S.; DiTusa, C.A.; et al. In vitro and in vivo efficacy and in vitro metabolism of 1-phenyl-3-aryl-2-propen-1-ones against Plasmodium falciparum. Bioorgan. Med. Chem. Lett. 2006, 16, 5682-5686. [CrossRef] [PubMed]

25. Yadav, N.; Dixit, S.K.; Bhattacharya, A.; Mishra, L.C.; Sharma, M.; Awasthi, S.K.; Bhasin, V.K. Antimalarial Activity of Newly Synthesized Chalcone Derivatives In Vitro. Chem. Biol. Drug Des. 2012, 80, 340-347. [CrossRef]

26. Bondock, S.; Gieman, H.; El-Shafei, A. Selective synthesis, structural studies and antitumor evaluation of some novel unsymmetrical 1-hetaryl-4-(2-chloroquinolin-3-yl)azines. J. Saudi Chem. Soc. 2016, 20, 695-702. [CrossRef]

27. Aminake, M.N.; Mahajan, A.; Kumar, V.; Hans, R.; Wiesner, L.; Taylor, D.; de Kock, C.; Grobler, A.; Smith, P.J.; Kirschner, M.; et al. Synthesis and evaluation of hybrid drugs for a potential HIV/AIDS-malaria combination therapy. Bioorgan. Med. Chem. 2012, 20, 5277-5289. [CrossRef] [PubMed]

28. Walsh, J.J.; Coughlan, D.; Heneghan, N.; Gaynor, C.; Bell, A. A novel artemisinin-quinine hybrid with potent antimalarial activity. Bioorgan. Med. Chem. Lett. 2007, 17, 3599-3602. [CrossRef]

29. Nqoro, X.; Tobeka, N.; Aderibigbe, B.A. Quinoline-Based Hybrid Compounds with Antimalarial Activity. Molecules 2017, 22, 2268. [CrossRef] [PubMed]

30. Verma, S.; Deshpande, S.; Pandey, S.; Agarwal, P.; Saxena, J.K.; Srivastava, K.; Chauhan, P.M.S.; Prabhakar, Y.S. N-(7Chloroquinolinyl-4-aminoalkyl)arylsulfonamides as antimalarial agents: Rationale for the activity with reference to inhibition of hemozoin formation. RSC Adv. 2016, 6, 25584-25593. [CrossRef]

31. Soares, R.R.; da Silva, J.M.F.; Carlos, B.C.; da Fonseca, C.C.; de Souza, L.S.A.; Lopes, F.V.; Dias, R.M.D.P.; Moreira, P.O.L.; Abramo, C.; Viana, G.H.R.; et al. New quinoline derivatives demonstrate a promising antimalarial activity against Plasmodium falciparum in vitro and Plasmodium berghei in vivo. Bioorgan. Med. Chem. Lett. 2015, 25, 2308-2313. [CrossRef]

32. Fisher, G.M.; Tanpure, R.P.; Douchez, A.; Andrews, K.T.; Poulsen, S.-A. Synthesis and Evaluation of Antimalarial Properties of Novel 4-Aminoquinoline Hybrid Compounds. Chem. Biol. Drug Des. 2014, 84, 462-472. [CrossRef]

33. Salahuddin, A.; Inam, A.; Van Zyl, R.; Heslop, D.C.; Chen, C.-T.; Avecilla, F.; Agarwal, S.M.; Azam, A. Synthesis and evaluation of 7-chloro-4-(piperazin-1-yl)quinoline-sulfonamide as hybrid antiprotozoal agents. Bioorgan. Med. Chem. 2013, 21, 3080-3089. [CrossRef]

34. Pandey, S.; Agarwal, P.; Srivastava, K.; Rajakumar, S.; Puri, S.K.; Verma, P.; Saxena, J.; Sharma, A.; Lal, J.; Chauhan, P.M. Synthesis and bioevaluation of novel 4-aminoquinoline-tetrazole derivatives as potent antimalarial agents. Eur. J. Med. Chem. 2013, 66, 69-81. [CrossRef] [PubMed]

35. Ishikawa, M.; Hashimoto, Y.J. Improvement in Aqueous Solubility in Small Molecule Drug Discovery Programs by Disruption of Molecular Planarity and Symmetry. Med. Chem. 2011, 54, 1539-1554. [CrossRef] [PubMed]

36. Zhou, L.; Yang, L.; Tilton, S.; Wang, J. Development of a high throughput equilibrium solubility assay using miniaturized shake-flask method in early drug discovery. J. Pharm. Sci. 2007, 96, 3052-3071. [CrossRef] [PubMed]

37. Makler, M.T.; Piper, R.; Williams, J.A.; Gibbins, B.L.; Hinrichs, D.J.; Ries, J.M.; Bancroft, J.E. Parasite Lactate Dehydrogenase as an Assay for Plasmodium falciparum Drug Sensitivity. Am. J. Trop. Med. Hyg. 1993, 48, 739-741. [CrossRef] [PubMed] 